\title{
Review on the influence of process parameters in incremental sheet forming
}

\author{
Shakir Gatea ${ }^{1} \cdot$ Hengan Ou $^{1} \cdot$ Graham McCartney $^{1}$
}

Received: 22 October 2015 / Accepted: 25 January 2016/Published online: 23 February 2016

(C) The Author(s) 2016. This article is published with open access at Springerlink.com

\begin{abstract}
Incremental sheet forming (ISF) is a relatively new flexible forming process. ISF has excellent adaptability to conventional milling machines and requires minimum use of complex tooling, dies and forming press, which makes the process cost-effective and easy to automate for various applications. In the past two decades, extensive research on ISF has resulted in significant advances being made in fundamental understanding and development of new processing and tooling solutions. However, ISF has yet to be fully implemented to mainstream high-value manufacturing industries due to a number of technical challenges, all of which are directly related to ISF process parameters. This paper aims to provide a detailed review of the current state-of-the-art of ISF processes in terms of its technological capabilities and specific limitations with discussions on the ISF process parameters and their effects on ISF processes. Particular attention is given to the ISF process parameters on the formability, deformation and failure mechanics, springback and accuracy and surface roughness. This leads to a number of recommendations that are considered essential for future research effort.
\end{abstract}

Keywords Single-point incremental forming · Formability · Failure mechanisms $\cdot$ Springback $\cdot$ Surface roughness

Shakir Gatea

epxsmg@nottingham.ac.uk

Hengan $\mathrm{Ou}$

h.ou@nottingham.ac.uk

1 Department of Mechanical, Materials and Manufacturing Engineering, Faculty of Engineering, University of Nottingham, Nottingham NG7 2RD, UK

\section{Introduction}

Incremental sheet forming (ISF) generally refers to a group of forming processes that may be characterised by localized deformations, and these deformations are proceeded progressively on a certain path to cover the whole surface of the part. Depending on this definition, there are several types of ISF, such us spinning, shear forming, flow forming and single- or two-point ISF. In spinning, a roller is used to push a rotating blank gradually onto a mandrel to produce an axisymmetric shape with respect to the profile of the mandrel. A similar approach is used in shear forming, but it is designed to use a large force to produce a hollow or tubular part.

The main difference between spinning, shear forming and flow forming is in the thickness of the formed parts. Parts formed by spinning process show less change in thickness as compared with those formed by shear forming and flow forming processes. Several ISF techniques have been developed to make use of computer numerical controlled (CNC) equipment. One of these methods, single-point incremental forming (SPIF), may be characterised by the action of a CNC milling machine tool that has a single-point contact with the sheet metal blank. The blank is fixed by a holder that remains at the same height, as shown in Fig. 1 [1]. In this process, a small-sized hemispheric tool moves along a user-defined path and incrementally creates the desired shape [2].

One of the earliest research publications on ISF was by Leszak in 1967 in a patent [4] at the time when a CNC machine was not yet technically feasible. In the late 1970s and early 1980s, the principle of asymmetrical incremental sheet metal forming was first described by Mason and Appleton [5, 6]. They proved that the flexible forming of a sheet metal workpiece was possible by using a hemispherical tool that can be moved along a three-axis CNC mill. Since then, many research papers have been published in this field. However, 


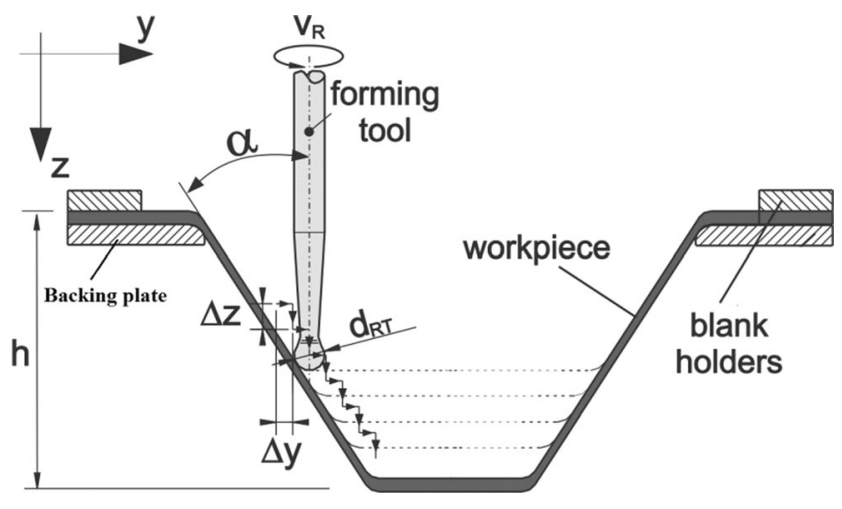

Fig. 1 Basic principle of incremental sheet forming [3]

ISF is still under development in a number of areas requiring further research before this technology is used within industry, although the potential areas for applications have already been highlighted and clear advantages have been established as against conventional sheet metal forming techniques.

Recently, a number of review papers have been published to present overview on ISF processes. A comparison between traditional and modern sheet metal forming was presented by Hagan and Jeswiet [7] to illustrate the different characteristics of the ISF process. The modifications that have been made to conventional sheet metal forming such as spinning and shear forming were described by Jeswiet et al. [8], and it was focused on an asymmetric single-point incremental forming (AISF), which provided a valuable guideline for designers and manufacturers. Micari et al. [9] discussed some relevant issues concerning SPIF. It was recognized that the geometrical accuracy is considered one key weakness of SPIF, which may be compensated for by tool path optimization. Six mechanisms were discussed by Emmens and van den Boogaard [10] to understand the deformation mechanisms and formability in ISF. It is found that the contact stress, bending-under tension and shear mechanisms play a key role in localized deformation whilst cyclic straining, geometrical instability and hydrostatic stress mechanisms have an effect in postponing the growth of necking. Hydrostatic pressure cannot explain stability above the forming limit curve but might have an effect on final failure. Emmens et al. [11] gave a comprehensive review of historical development of ISF, and they found that most patents refer to two-point incremental forming (TPIF) as a process, just one patent related to the formability. An overview of the current state of development of hybrid AISF was presented by Taleb Araghi et al. [12]. It was concluded that stretch forming combined with ISF and laser-assisted AISF can be used to improve the sheet thickness distribution and accuracy of the final part. With most of previous reviews focusing on the historical development and deformation mechanisms of ISF, it is considered a useful addition to have a detailed review focusing on ISF process parameters and their effects on the finished parts as this is believed to be a specific area that is important to move the ISF-centred process to the next level of technological maturity.

Therefore, this review paper aims to provide a detailed analysis of a number of critical research issues of ISF. It discusses the current state of fundamental understanding, technological capabilities and limitations, recent developments and current research challenges with a particular attention given to the formability, deformation and failure mechanics, springback and accuracy and surface roughness.

According to the forming method, the ISF technology can be classified as SPIF and TPIF, in which the tool moves around a partial or fully fixed die on a programmed path to pull down the sheet. Figure 2 illustrates the TPIF process. Further classification can be made by the types of processes that are applied, such as Negative or Positive. These types of ISF processes can be seen in Fig. 3. In Negative ISF, the force is applied inside the cavity to be formed and the application of positive force is the outside of the part. The Positive process always happens in TPIF, where it is necessary to have a die that is located inside the part. This is because the tool force is applied on the convex side of the shape, to follow the contour lines. Negative increment sheet forming might be applied to both processes, depending on the component characteristics [13].

According to the technical characteristics presented, SPIF can be used for small batch production, prototypes and customised products. For example, in the rapid prototyping, Jeswiet et al. $[15$,$] used SPIF to produce prototypes for the$ automotive industry. In the field of medical applications, Verbert et al. [16] produced a titanium skull implant by using multi-stage SPIF.

The advantages that allow ISF to be developed as a viable solution for sheet metal products can be listed as follows:

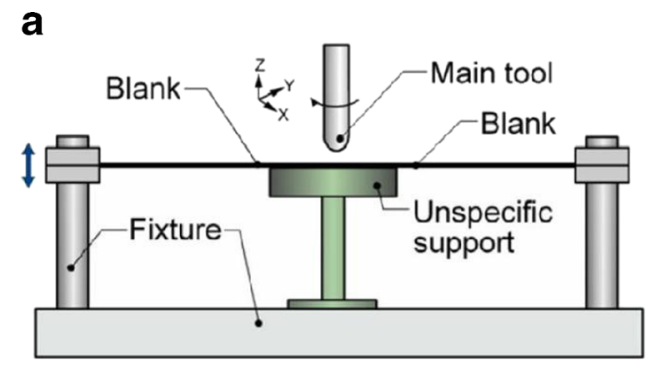

b

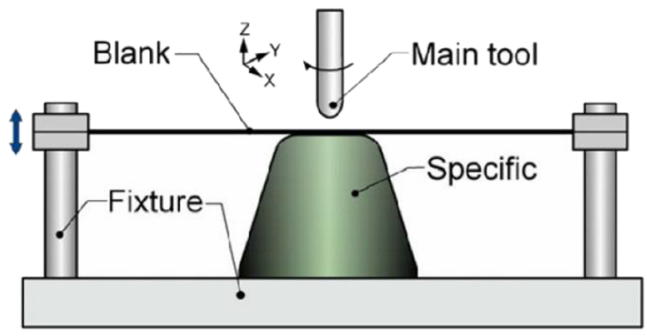

Fig. 2 a TPIF with partial die; b TPIF with full die [14] 

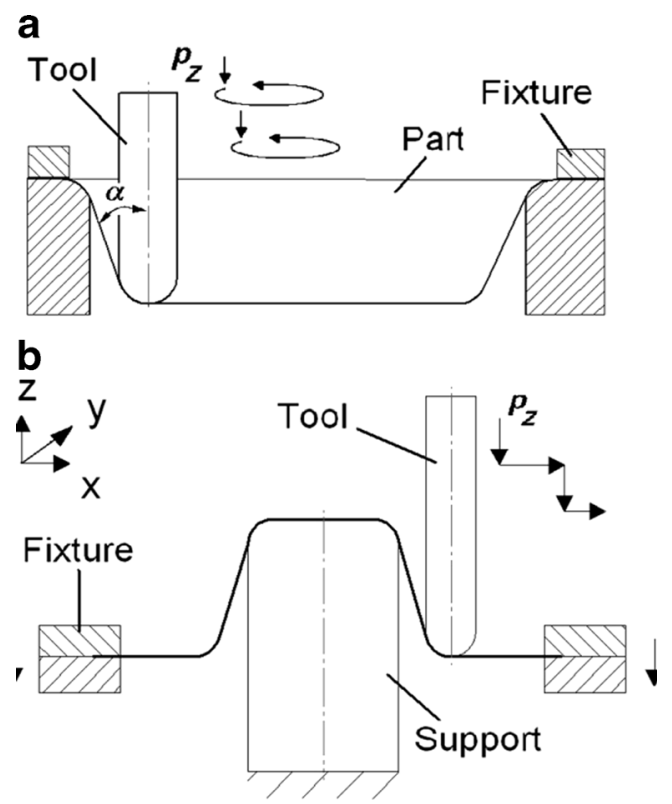

Fig. 3 Forming principle of ISF a Negative forming and $\mathbf{b}$ Positive forming [13]

- The setup costs can be largely neglected [9]

- ISF is a highly flexible process, and it is possible to simply modify the machine part program so that the product shape is changed [17].

- Due to the stress state induced during tool movement, the formability is greater than that of traditional stamping [9].

- ISF is suitable to make parts for replacement, such as for automotive parts where there is a lack of dies and tooling for a one-off part, and it can also be used for rapid prototyping of new products [9].

- The contact surface is small, and the forces during the forming process are low so the amount of lubricant required is reduced as compared to conventional sheet metal forming [17].

On the other hand, there are some significant drawbacks of the process, which may be due to the following:
- ISF requires a significant amount of time to form the part as deformation is processed gradually by the defined tool path [9].

- The accuracy of the final part is normally inferior to that in a conventional stamping process with a significant amount of springback to occur during tool movement and trimming of the blank.

- It is difficult to produce a part with a wall angle close to $90^{\circ}$, hence many stages of ISF forming are needed to prevent failure [18].

- There are other limitations including material thinning and poor surface finish.

This paper is organized as follows: Sect. 2 gives an overview of the ISF formability and the effect of process parameters on formability with suggested measures for improvement. In Sect. 3, a review and discussions are presented on the mechanical fracture and deformation mechanisms in SPIF. Section 4 introduces the shape distortion and springback effects arising from SPIF with detailed discussion on the effect of tool path, forming parameters and resultant residual stresses. Different algorithms are explained in Sect. 5 to improve the surface finish of ISF processed parts. Finally, conclusions and recommendations for future research are drawn in Sect. 6.

\section{Formability in SPIF}

In general terms, formability in sheet metal forming is the ability of a given metal to deform without exhibiting specific forms of failure. Formability in SPIF can be defined by the maximum wall angle (see Fig. 4), and it is measured in terms of a tangent line from the unformed blank to the deformed part of the surface, determined by sine law, $t_{f}=t_{i} \sin (\pi / 2-)=t_{i}$ $\sin \alpha$, where $t_{i}$ and $t_{f}$ are the initial and final thicknesses of the part, respectively, and $\alpha$ is the semicone angle [19]. Thus, $\max$ is usually used as a parameter to measure whether the SPIF

Fig. 4 Schematic representation of a cross-sectional view of the rotationally symmetric SPIF process [20]

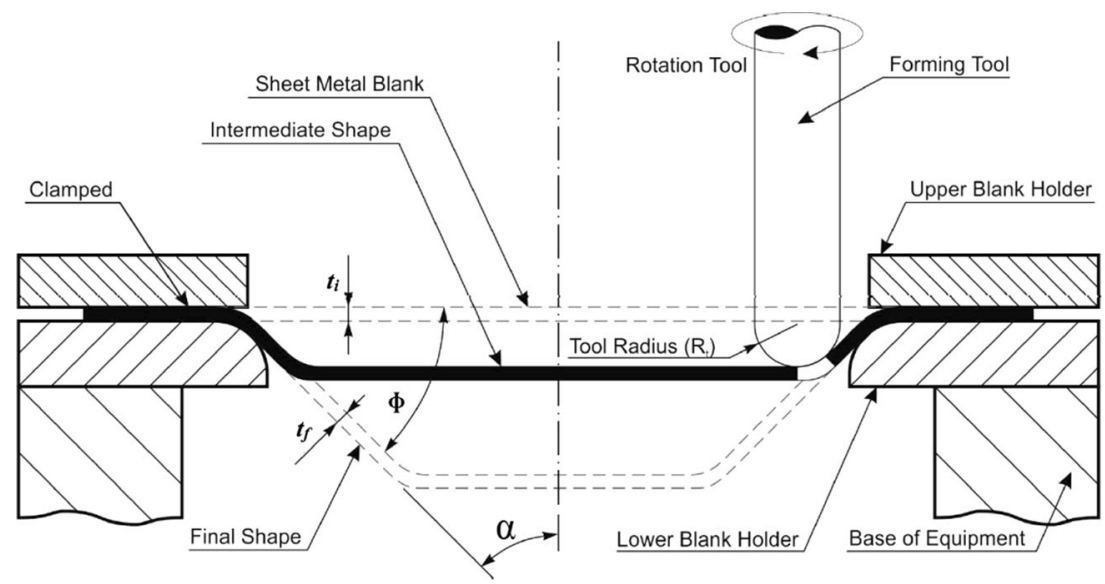


process is a suitable forming application for a given material and sheet thickness.

There are different opinions about the modes of deformation in SPIF. Based on experimental work and finite element (FE) simulation, some authors think that the deformation occurs due to shearing [21], whilst others believe it is through stretching [22]. In SPIF, a forming limit diagram (FLD) is used to describe the formability of materials. The forming limit curve (FLC) is usually employed to determine the limits of proportional straining before failure and is quite different from the corresponding one in traditional forming, as shown in Fig. 5 [23].

One of the main limitations of ISF is thickness reduction. A double-pass forming method was proposed by Kim and Yang [24] to improve the formability of aluminium sheets in ISF. It was shown that the majority of deformation occurs by shear, which is an important factor to improve the formability. More uniform thickness strain distribution of the respective products is possible when using the double-pass forming method than with other methods. Myoung-Sup and Jong-Jin [2] investigated the formability of aluminium sheet (Al 1050) in ISF, using a tool with a freely rotating ball. It was found that the formability of the sheet shows a special shape on the strain path and appears as a straight line in the FLD. Forming limit diagrams were developed for ISF of 3003 aluminium sheet, using SPIF by Young and Jeswiet [15]. FLDs were defined according to five distinct shapes: a hemisphere, a straight-sided cone, a hyperbolic-sided cone, a pyramid and a shape with five lobes. It was noticed that very high strain of over 300 per cent can be achieved with SPIF. Han and Mo [25] developed a three-dimensional elasto-plastic finite element model to investigate the 08Al ISF process. All results were compared with those of experiments. Good agreement between simulated and experimental results in terms of the radial strain and thickness distribution was found. Furthermore, less thinning and more homogenous plastic strain and thickness distribution were achieved with reduced incremental step depth and increased tool size and wall angle. Jun-chao et al. [26] carried out numerical simulation and tensile tests of the thickness distribution and mechanical property of a truncated pyramid (Dc04 sheet). The results demonstrated that the minimum thickness was closely related to ISF tool diameter if a conventional tool path was employed and its location was largely determined by the step size. Tensile test samples were taken from the formed pyramid. It was found that the plasticity of sheet material dropped suddenly while the strength rose. Junchao et al. [27] established a finite element model for a double-pass forming to study the deformation characteristics of multi-stage forming of ISF. The blank was used in the experiment on a DC56 sheet, which showed that a double-pass forming process enabled more uniform thickness distribution, due largely to the benefits from the increase of the total plastic deformation zone. Junchao et al. [28] devised a series of multi-pass ISF experiments to study the effect of the number of forming stages (n) and angle increments between two adjacent stages $(\Delta \alpha)$ on the DC56 sheet formability. It was found that, with the increase of forming stages, the minimum thickness rises significantly and more uniform thickness distribution is accomplished. Moreover, the maximum thickness reduction drops initially and goes up as the value of $\Delta \alpha$ increases. Titanium F67 grade 2 sheet was used by Silva et al. [29] to determine the thickness distribution of
Fig. 5 Forming limits diagram of SPIF against traditional sheet forming [23]

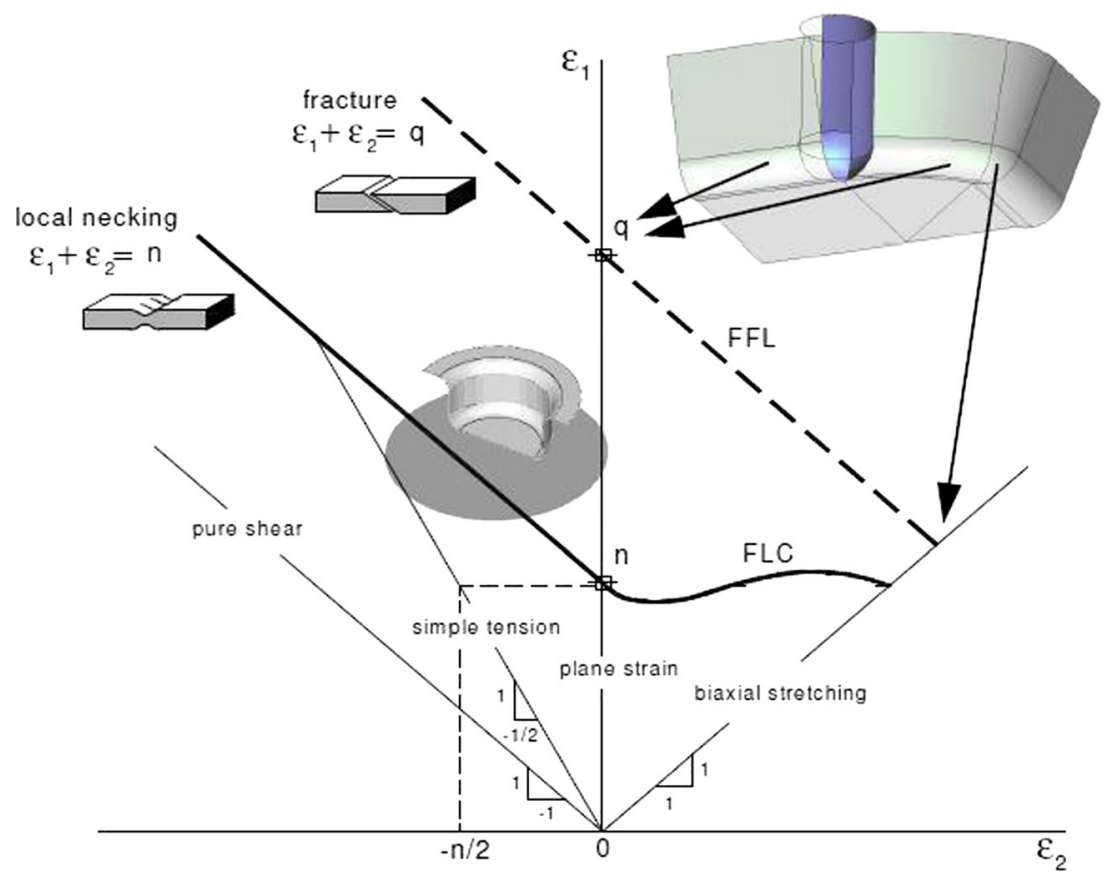


formed sheet by using SPIF. The measurement of thickness and true strain showed that the limit wall angle of the titanium sheet with $0.5-\mathrm{mm}$ thickness is $47^{\circ}$. In addition, the workpiece thickness is $0.35 \mathrm{~mm}$ according to sine law, as compared to approximately $0.25 \mathrm{~mm}$ from experiment. There are many factors which affect the formability of materials. However, the main factors in the SPIF include forming temperature, forming angle, step size, tool rotation, feed rate, tool size and tool path, and these will be considered in the following section.

\subsection{Effect of process parameters on formability}

\subsubsection{Forming temperature}

Studies have been undertaken to evaluate the effect of temperature on the formability of materials. A laser-based heating system was used by Duflou et al. [30], to create a heated spot in the moving contact zone between tool and titanium TiAl6V4 blank. The results showed that the formability of material was increased by laser-based heating. Ji and Park [31] attempted to use magnesium sheets in incremental forming at warm condition. It was found that with magnesium alloy, AZ31sheet formability increased as the temperature increased from 20 to $250{ }^{\circ} \mathrm{C}$. The use of an electrical current for heating hard-to-form sheet metal at the tool-blank interface was proposed by Fan et al. [32] for hot incremental forming, as shown in Fig. 6. It was found that when the electric current was increased, the formability of hard-to-form sheet metal increased as well. Moreover, the yield strength in the tool-blank contact zone was reduced, so the wall angle and formability of magnesium alloy AZ31 increased. Recently, Liu et al. published a paper in developing electricity-assisted ISF by using new forms of ISF tooling with cooling channels to form titanium Ti6Al4V sheets with improved formability to this hard-to-form material [33].

Fig. 6 The principle of electric incremental forming [32]
Göttmann et al. [34] introduced a new concept for laser-assisted AISF, as shown in Fig. 7. The tool path was programmed by the CAX tool. Experimental results showed that the formability of the titanium grade 5 (TiAl6V4) alloy increased. Mosecker et al. [35] investigated the temperature effect on the microstructural evolution of the deformed workpiece. They formed longitudinal pockets with different depths by using a laser-assisted ISF. It was found that without cooling, deformation at $850{ }^{\circ} \mathrm{C}$ led to the highest deformation depth accompanied by pronounced hardening of the material due to grain refinement. On the other hand, good results were yielded from cooling to a coarse globular microstructure with lower hardness and nearly homogenous thickness reduction. An apparatus was constructed by Adams and Jeswiet [36] to improve the formability of 6061-T6 Al employing SPIF process. This apparatus can be used to apply large direct current to the rotating tool. Several current setting and tool diameters were tested to determine the maximum wall angle. It was noticed that the formability increased at the same current density with different tool diameters, so the current density was considered to be a more important factor rather than the current magnitude. Therefore, a general condition is that the formability improves with the increase of forming temperature, but this needs additional equipment (e.g. a heat source); therefore, it is suitable to use hot ISF only in cases where the cost is not taken into account.

\subsubsection{Forming angle}

In SPIF, the maximum forming angle is considered to be one of the most important criteria to measure the material's formability limit. Two experiment designs were presented by Ham and Jeswiet [37] to investigate the effect of forming parameters in SPIF and the degree to which they affect aluminium AA3003 formability. The experiment showed a small effect of

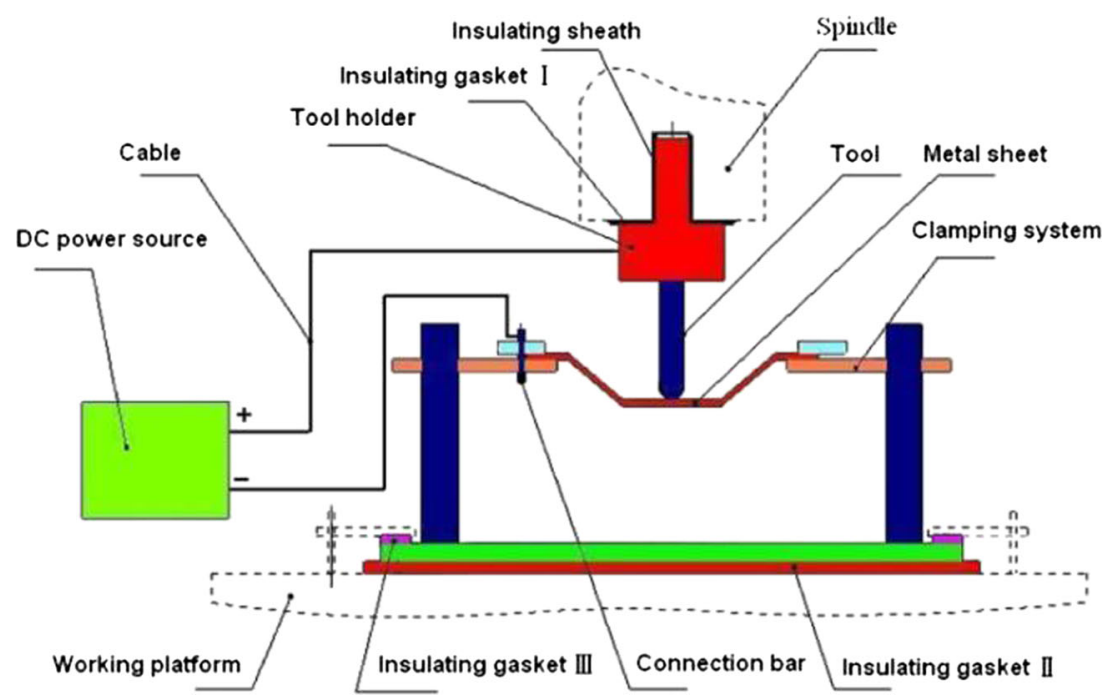




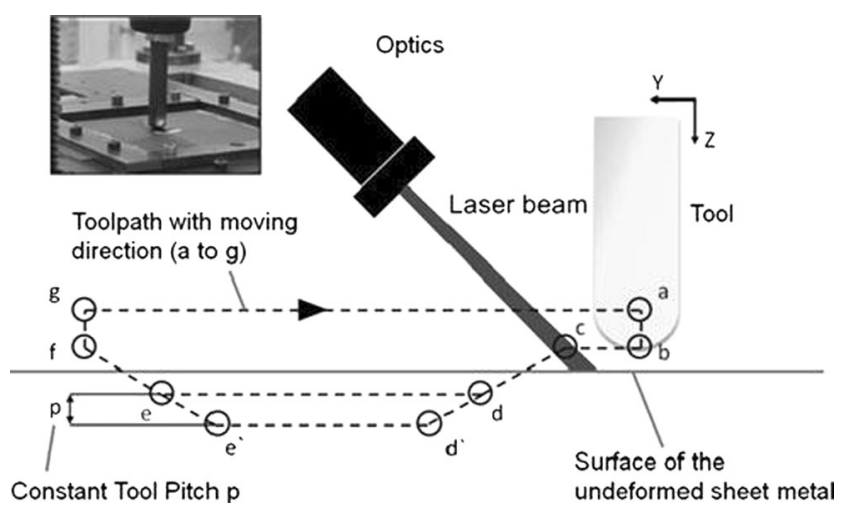

Fig. 7 Experimental setup laser spot, forming tool and the procedure for the forming process [34]

the step size on the maximum forming angle within $1^{\circ}$ of difference, whereas the material's thickness, tool diameter and interaction between the material thickness and tool size had a significant effect on maximum wall angle. Minutolo et al. [38] determined the maximum slope angle of the frustums of a pyramid and cone by forming aluminium 7075T0 sheet. The practical test program has led to an evaluation of the maximum wall angle: $63^{\circ}$ for a frustum pyramid and $66^{\circ}$ for a frustum cone. An experimental study was undertaken by Bhattacharya et al. [39] to illustrate the effect of ISF process variables on the maximum wall angle of an Al5052 blank. Analyses of experimental results indicated that the formable angle decreased with increased tool size and incremental depth and decreased blank thickness, whereas feed rate did not have a significant effect on the formable angle. Radu [40] tested two geometries of parts and three thicknesses of metal sheets in order to determine the maximum forming angle of a DC01 carbon steel sheet. It was possible to produce shapes with wall slope of up to $80^{\circ}$ and a depth of up to $70 \mathrm{~mm}$ from sheet metal blanks no thicker than $1.2 \mathrm{~mm}$ by using a simple tool. The behaviour of brass 70/30 sheet under ISF conditions was addressed by Fritzen et al. [41] with the consideration of the following parameters: wall angle, step depth and tool path strategy. Experimental tests explained that the spiral tool path yielded a greater forming angle as compared with the traditional tool path. It can be seen from the above investigations that many parameters have a big effect on the wall angle, e.g. tool diameter and tool path, although further study is needed in order to determine the range of their effects on the wall angle (e.g. step size and feed rate).

\subsubsection{Incremental depth (step size)}

The influence of incremental depth is still a debatable parameter. Theoretical investigation was achieved by Ambrogio et al. [42] to get a deeper understanding of the basic phenomena involved in SPIF. The analysis showed that a negative stress distribution occurs under the tool contact zone and tensile stresses on the walls of the formed part. These stresses decrease with decreased incremental depth. Ham and Jeswiet [37] studied the formability of aluminium AA3003 sheets in two new experiment designs in SPIF, and they found that the incremental depth had a significant influence on the formability and that decreased step size improved the likelihood of the part to be formed. Kim et al. [43] studied the ISF process to produce a complex geometric shape (human face) by using FE simulation and Taguchi's method. Finite element method (FEM) simulation was implemented and evaluated from the historical strain and stress values of cold rolled steel. FE results based on the Taguchi array showed that the tool downstep was identified as an important factor for improving the formability. The effect of some parameters, such as step size, on the formability of a commercially pure titanium blank was investigated by Hussain et al. [44], and the results proved that the formability decreases linearly as the step size increases. Experimental investigation by means of surface 3D digital image correlation was published by Decultot et al. [19] in forming of an AW-5086-H111-grade aluminium alloy. It was found that the workpiece formability was reduced with the increase of increment step size. An experimental study using aluminium Al3003-0 was undertaken by Duflou et al. [45] to measure the force in SPIF. It was noticed that the vertical step size had the least significant impact, according to the study by Fritzen et al. [41] to address the behaviour of $30 / 70$ brass sheet in ISF. When the vertical step was decreased to $0.5 \mathrm{~mm}$, there was a gain of $1^{\circ}$ in the forming angle with a $100-\mathrm{mm}$ depth without failure. It can be concluded that there is a gap of understanding on the influence of step size in ISF. Hence, more research needs to be carried out into the effect of different materials in order to find the relationship between step size and the formability of different materials.

\subsubsection{Forming speed (rotation and feed rate)}

Forming speed has a considerable influence on sheet formability with both rotational speed and feed rate considered important factors in SPIF. The relative motion between the tool and blank is directly proportional to the heat generated by friction. However, it is generally believed that the formability increases along with the forming speed due to heating effects. Ham and Jeswiet [37] presented two experimental designs to investigate the formability of aluminium AA3003 sheets in SPIF. Tool setups were at higher rotational speeds and thus generated more frictional heating in the contact zone, and it was found that the higher rotational speed improved formability. In addition, the blank formability is improved by reducing the feed rate. Producing dome geometry by SPIF was studied by Rattanachan and Chungchoo [46] to explain the effect of speed on the formability of DIN 1.0037 steel (St 37-2 steel). The results showed that the tool rotational speed had more influence on formability and that when tool rotational speed 
increased, the formability decreased. On the other hand, the tool feed rate had less influence on formability, with the results showing decreased formability at increased feed rate. A cold incremental forming process was carried out by Hussain et al. [44] in order to investigate the effects of some parameters on formability (maximum wall angle) of commercially pure titanium $(\mathrm{Cp} \mathrm{Ti})$ sheet. It was observed that an increase in the feed rate decreased the formability and that the relationship between feed rate and maximum wall angle was in a quadratic curve. Buffa et al. [47] proposed a method for enhancing the formability of materials in SPIF using high tool rotation speed. This technique was applied on poor formability materials at room temperature, e.g. aluminium AA1050-O, AA1050-H24 and AA6082-T6 sheets. The experimental results showed that there was an increase in drawing angle around $7.5^{\circ}$ to $12.5^{\circ}$, as compared to conventional SPIF process. It can be clearly seen that the effects of tool rotation are debatable. Therefore, there is a clear need for further research to the effect of tool rotation on ISF formability to establish a quantitative tool rotation and feed rate for different materials. The establishment of such a quantitative relationship would help provide a guideline of the optimum tool rotation and feed rate for a given material.

\subsubsection{Tool size and shape}

Tool size is an important factor on the formability of materials in SPIF. Experiments have proven that a smaller tool radius enables a higher formability than can be achieved by a larger one. Furthermore, better support of sheet metal can be obtained with large tool diameters, due to a bigger contact zone, and the amount of forming force increases when the contact area increases between the tool and blank. In the case of a small tool radius, there is a highly concentrated zone of deformation that causes high strain and leads to better formability. Hussain et al. [44] evaluated the formability of a Cp Ti sheet in cold ISF process in order to investigate the effect of tool diameter on the formability. The tool diameter was varied over three levels, i.e. 8,12 and $16 \mathrm{~mm}$. It was found that by increasing the tool size, the formability decreases to approximately follow a quadratic relation.

Using a finite element model to investigate ISF of $08 \mathrm{Al}$ sheet, Han and Mo [25] found that reduced incremental depth and increased tool size and wall slope angle tend to reduce axial stress and material thinning and lead to more homogeneous distribution of thickness and plastic strain. The effect of tool diameter on the thickness was studied by Jun-chao et al. [26]. They found that the tool size showed little correlation to the location of the minimum thickness, but when tool diameter increases with a spiral tool path, the thickness increases continuously (Fig. 8). Moreover, the minimum thickness is closely associated with tool diameter if a conventional tool path is employed.

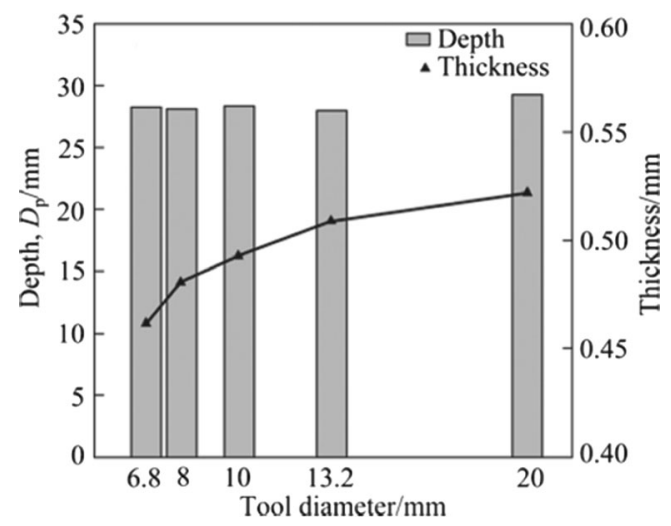

Fig. 8 Minimum thickness and its location under condition of varying tool diameters [26]

Ham and Jeswiet [37] illustrated the effect of tool diameter on the maximum forming angle for SPIF of aluminium AA3003 sheets and found that higher formability occurred with smaller forming tools due to the concentration of friction heat at the forming tool tip.

A Box-Behnken design of experiment was used by Ham and Jeswiet [48] to develop the experimental plan and to analyse data, and the results were presented as a response surface graph, which showed the effect of factors on the forming limit. It has been shown that when comparing the influence of material type on average effective strain, with the AA6451 having the lowest average effective strain when comparing tool diameter to average effective strain, aluminium AA5754 seems to have no effect as the contour is flat. With aluminium AA645 sheet, the largest tool diameter generates lowest average effective strain, and the other tool sizes have no effect on average effective strain.

A new oblique roller ball (ORB) tool has been developed by Lu et al. [49] to investigate the influence of friction on the material deformation and formability. Four grades of aluminium sheets were utilized in the experiments including AA110, AA2024, AA5052 and AA6111. A small hole in the sheet was drilled to study material deformation under both traditional rigid tool and the ORB tool. Experimental results showed that higher formability and smaller through-thickness shear are obtained with the ORB tool.

\subsubsection{Tool path}

Tool path generation is one of the most important factors that must be taken into account in ISF. It plays an important role to the final outcome, especially on thickness distribution of the formed product. Several types of tool paths were tested by Yamashita et al. [50] in order to determine the influence of the tool path on the deformation behaviour, using a finite element model (DYNA3D/ explicit code). Depending on the formed part and thickness strain distribution for various tool paths, the 


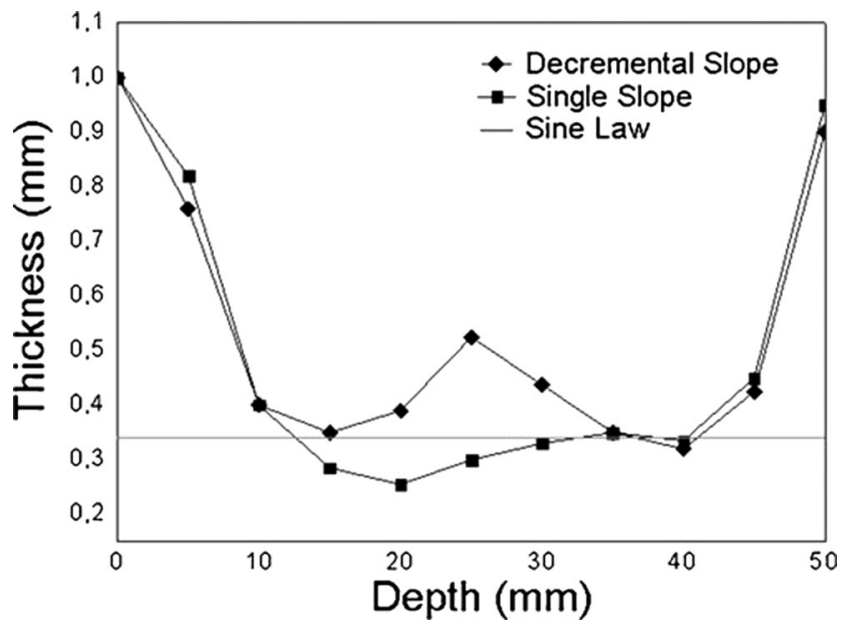

Fig. 9 Sheet thickness distribution as a function of depth [52]

travelling tool should be started from one of the corners of the product for a better shape. Otherwise, it is better for the tool to move in the horizontal and vertical directions simultaneously (i.e. in a helical manner) to get more uniform thickness distribution in the product. Mechanism of NC sheet metal in the ISF was presented by Zhou [51]. Due to the fact that the deformation of the blank occurs only around the tool tip and the contact area (deformation region) and is subject to stretch deformation, the thickness of the deformed area of the sheet reduces and the surface area increases. The purpose of sheet metal forming in steps is to produce the whole sheet deformation. From experimental results, in the case of the parallel line tool trajectory, a uniform thickness distribution of the deformed part is maintained and correlates with that obtained by sine law. Tool path optimisation was determined by finite element method in corporation with a response surface method (RMS) and sequential quadratic programming (SQP) algorithm, by Azaouzi and Lebaal [52], in order to improve thickness distribution of an asymmetric part. It was observed that after the third iteration, the optimal solution provided an improvement of about $7 \%$ the sheet thickness distribution (Fig. 9).

In order to overcome the problem related to inhomogeneous thickness distribution in aluminium AA1050-O part, an optimisation model was defined by Luigino et al. [17] to optimise tool path design by using a new trajectory according to the decremental slope differential of $\pm 10^{\circ}$. Significant reduction in the localised thinning was observed when compared to both the non-optimised tool path and the optimised one (Fig. 10).

Experiments were carried out by Liu et al. [53] to investigate and understand the formability and forming process mechanism of aluminium AA7075-O sheets in SPIF process. No difference was noticed in formability when the same part was formed with helical and Z-level tool paths. In addition, the same resultant force was obtained with both tool paths, but the force curve was smoother with the helical tool path.

\section{Deformation and failure mechanics in SPIF}

In sheet metal forming, the failures occur due to a number of mechanisms including the following: (A) void nucleation and coalescence; (B) shear band formation and (C) necking instability [54]. So, to understand how failure develops in SPIF, deformation modes and states of strain and stress in the deformation zone should be known. In SPIF, there is more than one deformation mode, as shown in Fig. 11, including the following: (A) plane strain stretching conditions in flat surfaces; (B) plane strain stretching conditions in rotational symmetric surfaces and (C) equal bi-axial stretching conditions at corners. Additionally, there are possibilities of other deformation modes between these modes [55].

There are many ways to predict the onset of failure in sheet metal during forming processes, such as the FLD; forming
Fig. 10 Comparison of the thickness distributions [17] a

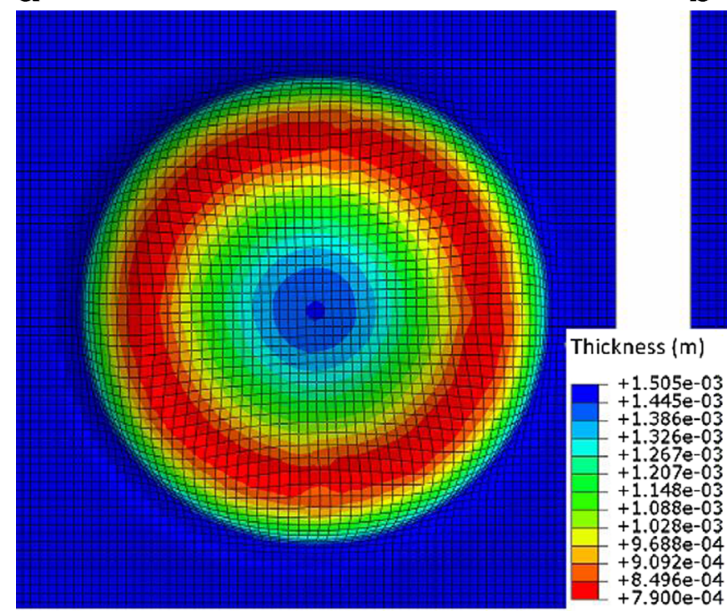

Before optimization b

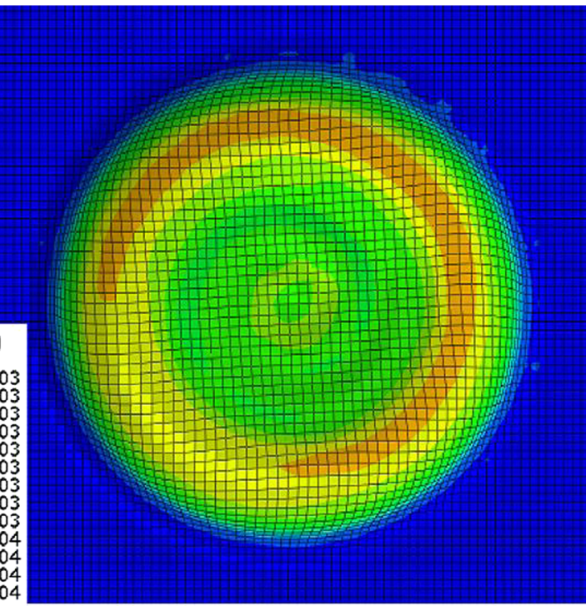

After optimization 


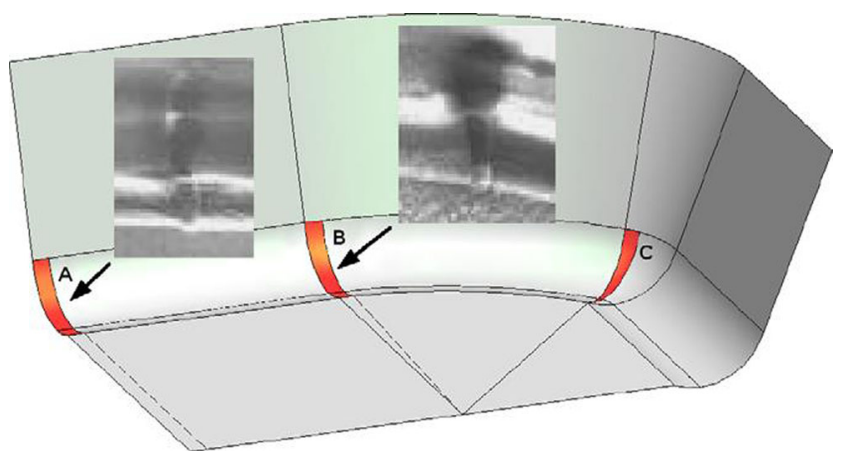

Fig. 11 Instantaneous deformation zone and contact area between forming tool and workpiece during SPIF [55]

limit stress diagram (FLSD); Müschenborn-Sonne forming limit diagram (MSFLD) and Marciniak-Kuczynski (M-K) criteria [56]. However, the FLD is considered the most well-known way of predicting failure in the ISF. Using the deformation mode, many researchers have tried to investigate the difference between the failure mechanisms of traditional sheet metal forming and ISF so as to give a specific answer to the question, "Does necking occur before fracture in ISF?", or "Does fracture take place without necking?" Therefore, this section is focused on the most studied deformation and failure mechanisms and the effect of key variables on failure.

\subsection{Effect of process parameters on deformation and failure mechanics}

\subsubsection{Stresses and strains in SPIF}

Stress triaxiality is used as a measure to consider the stress state's influence on failure modes, and strain represents one of the most important criteria to predict damage in SPIF. A theoretical model for the different modes of deformation is commonly found in SPIF, built upon membrane analysis and ductile damage mechanics by Martins et al. [55]. Experimental observations show that fracture is not preceded by localized necking, and the crack develops under tensile meridional stresses acting under stretching conditions (Fig. 12).

Another analytical model of SPIF was presented by Silva et al. [22] depicting membrane analysis and the experimental observation of the smear mark in the contact zone between the tool and sheet. This model proved that the cracks in SPIF were

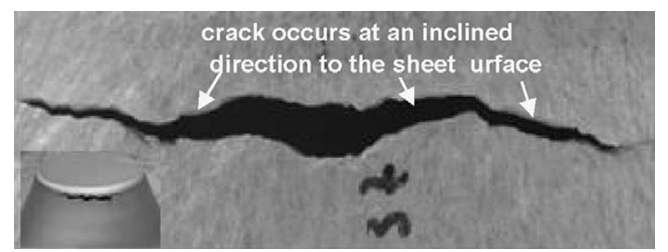

Fig. 12 Experimental evidence that SPIF is limited by fracture without necking [55] initiated by meridional tensile stresses but not by plane shearing stresses as shown in Fig. 13.

Specially prepared copper sheets were utilized by Jackson and Allwood [57] to experimentally examine the deformation mechanism of the ISF (SPIF and TPIF) and the accuracy of the sine law for prediction of wall thickness. The experimental results show that, firstly, the deformation mechanisms of both SPIF and TPIF happen in two planes: the first one perpendicular to the tool direction and the other parallel to the tool direction. Stretching and shear occurred in the first plane, and shear in the second plane. Secondly, the high percentage of stretching and shear in the tool direction accounts for differences between the sine law and measured wall thickness in SPIF and TPIF. Finally, the mechanisms of SPIF and TPIF differed from a mechanism of pure shear. Experimental work using a surface 3D digital image correlation approach was carried out by Decultot et al. [19] to show that the fracture occurred in the uniaxial stretching domain. To predict the occurrence of failure in the aluminium AA5052 sheet, Malhotra et al. [58] used explicit finite element analysis (FEA) with a damage-based fracture model, in which failure envelope depended on the hydrostatic pressure and the Lode angle. It was noted that the damage evolution was controlled by local bending around the tool and through-the-thickness shear. A fracture model combined with finite element analyses to predict the occurrence of fracture in SPIF was carried out by Malhotra et al. [59] for two shapesa cone and a funnel. An aluminium AA5052 sheet was used in this study. It was found that both through-the-thickness shear and local bending of the sheet around the tool had an effect on fracture in the SPIF technology. By using a newly developed solid-shell element, a preliminary study of the stress state was carried out to evaluate a near-to-failure SPIF cone by Guzmán and Habraken [60], for aluminium AA3003-O sheet. The results showed that the Lode angle can be used with Voce or Swift hardening, and it is able to capture the stress state change during SPIF. Furthermore, an experimental and numerical study was undertaken by $\mathrm{Xu}$ et al. [61] to investigate the effect of through-the-thickness shear on the formability of aluminium AA5052-H32 sheet in SPIF. A fracture model was developed to simulate a $70^{\circ}$ cone by SPIF and deep drawing. As a result, the fracture depth of the cone produced by SPIF was bigger than that of the same cone formed by deep drawing. Therefore, the through-the-thickness shear in deep drawing can be neglected as it is not significant as compared to that obtained in SPIF. In addition, the higher value of through-the-thickness shear in SPIF raises the value of the reference fracture strain, which results in lower damage accumulation. As a result, the through-the-thickness 
Fig. 13 Crack propagation in SPIF: a schematic illustration of the typical crack propagation path in SPIF; b circumferential zigzag crack propagation path; $\mathbf{c}$ circumferential straight crack propagation path; and $\mathbf{d}$ circumferential straight crack propagation path in a rotational symmetric part obtained by conventional deep-drawing [22]
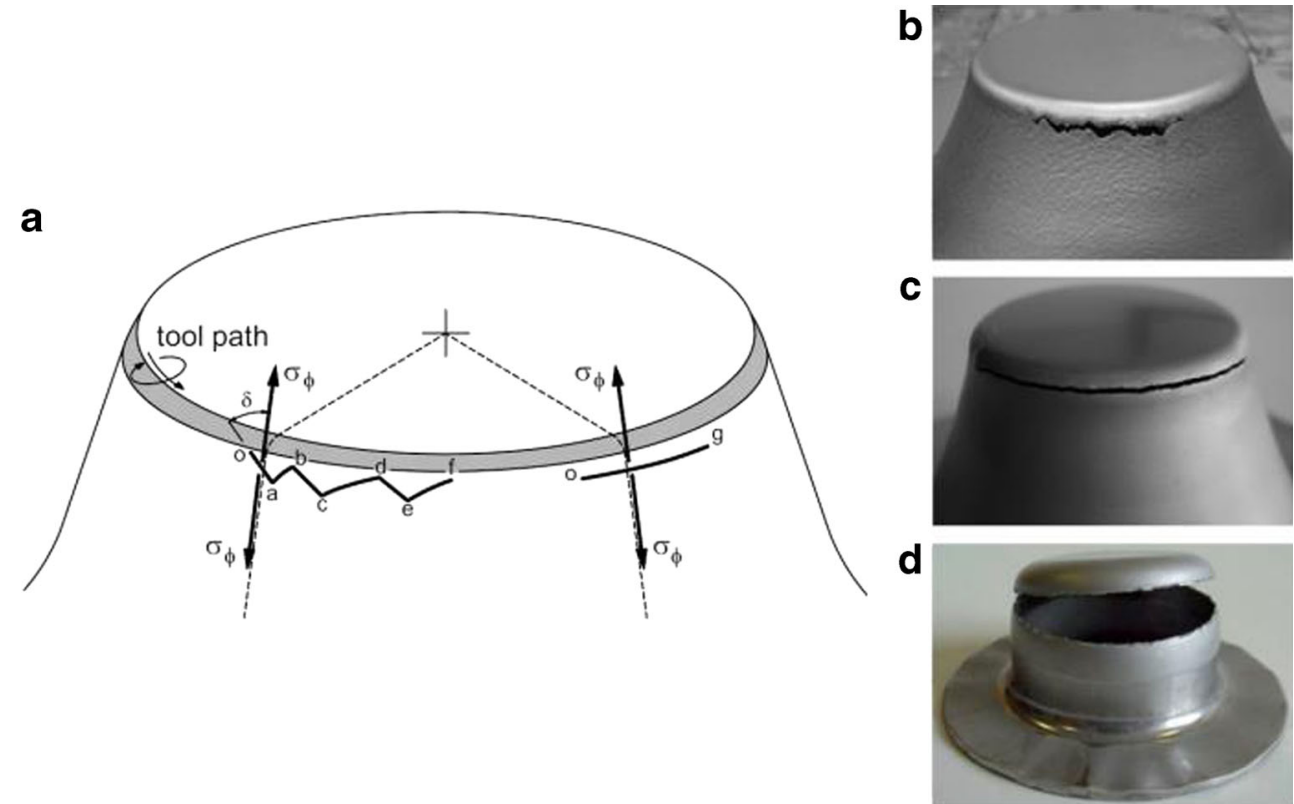

shear in SPIF is considered as a positive factor to material formability when it is within a certain range. Fang et al. [62] proposed an analytical model from their study to investigate the deformation mechanism and fracture behaviour in the SPIF technology. Both the bending effect and the strain hardening were considered based on the equilibrium approach. The result showed that the deformation takes place mainly in a meridional direction and small amounts of deformation occur in the circumferential direction. These deformations occur not just in the contact area but also on the inclined wall, and the fracture always occurs on the outer surface of the wall at the transition point between the contact and non-contact zones. It is clear from the above discussion that there is not a unified theory for failure in SPIF; due to the contradicting views on the effect of shear on fracture, some researchers confirm its important role in fracture with opposing views by others. Therefore, future work should focus on the fracture mechanism in ISF so that a unified model may be developed to accurately predict fracture in SPIF.

\subsubsection{Application of a forming limit diagram}

Depending on crack morphology and thickness measurements along the cross-section of the parts manufactured by SPIF, plastic deformation is revealed by uniform thinning until fracture, though there is no experimental evidence of necking taking place. Therefore, the forming limit curve at the necking (FLCN) of traditional sheet metal forming is not applicable to describe SPIF failure. Forming limit curve at fracture (FLCF) can be used to predict the fracture in ISF $[23,63]$. Most of the FLCs in ISF at fracture take the shape of a straight line with a negative slope in the first quadrant of the FLD. Ductile fracture criteria used in bulk forming processes are utilized to describe the FLD at fracture. The main idea of ductile fracture criteria is that the fracture happens when the maximum damage value of sheet metal exceeds a critical damage value (CDV) [64]:

$$
\int_{0}^{\varepsilon_{f}} F(\text { process parameters }) d \varepsilon=\mathrm{CDV}
$$

where $\varepsilon_{f}$ is the effective strain at fracture and $F$ is a function of the process parameters.

Based on ductile damage mechanics, Martins et al. [20] investigated the forming limit of aluminium AA1050-H111 sheet in SPIF. It was demonstrated that neck formation did not precede fracture. Therefore, the conventional FLC is not applicable when describing failure. Instead, a fracture FLD should be employed. Finite element method, combined with circle grid analysis, was used by Araujo et al. [65] in order to explain failure by cracking at the critical geometric features of facial implants and to assist in the overall design of a titanium grade 2 sheet. The fracture limit curves by cracking are characterised by means of a straight line with a slope equal to -0.8 and a maximum drawing angle of approximately $60^{\circ}$. In experimental testing, due to the fact that the maximum forming angle of titanium grade 2 has a rather low value, the side walls that surround and support the region of the sheet where the implant is located tend to crack and fail at a rather low angle. Several tests were developed for aluminium AA1050-O sheets, aiming to achieve different straining conditions to determine FLDs for the ISF process. It has been shown that ISF may be characterised by a local stretching and FLC which is quite different from a conventional one. 
Fig. 14 Illustrates comparisons between FEM and experimental work. a FEM based on MMFC to establish FLD, b FEM with regard to tool dimension to establish FLD, and c experimental work [66]

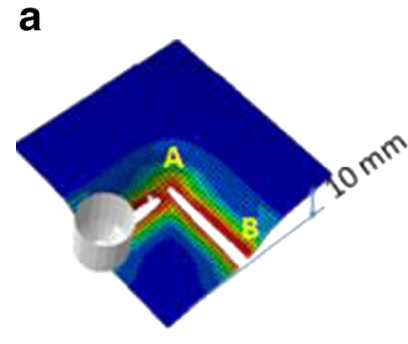

b

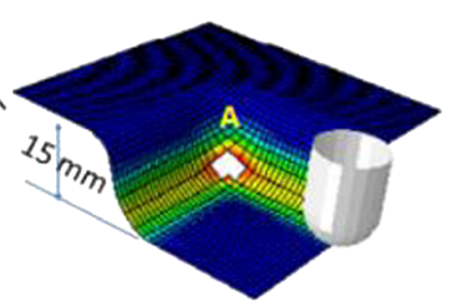

C

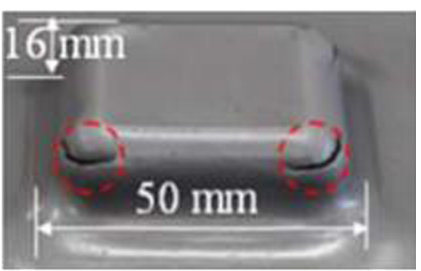

FEM simulation was coupled with FLD criterion by Nguyen and Kim [66] to predict the failure in the ISF process using 1-mm cold rolled steel sheet. The FLCF constructed from the modified maximum force criterion (MMFC) was first utilised to predict ductile fracture in an ISF simulation test, then the FLCF established with the consideration of tool dimension effect. Thereafter, the wall angle of a square shape was changed to determine its effect on fracture height and obtain the FLCF. It is clearly seen from Fig. 14 that the FLCF based on the MMFC is inaccurate, whereas there is a strong correlation when the FLCF is established according to tool diameter. In the case with a tool diameter $=12 \mathrm{~mm}$, feed rate $=600 \mathrm{~mm} / \mathrm{min}$ and incremental depth $=1 \mathrm{~mm}$, the maximum wall angle of a complex shape is lower than $68.2^{\circ}$. Stretching, stretch-bending and SPIF tests were carried out by Centeno et al. [67] to experimentally analyse the formability of an aluminium AA2024-T3 sheet. A Nakajima test was used to determine the FLD, and the FLCF was put to the test by evaluating the failure strains of stretch-bending and the SPIF. According to Fig. 15, it is clear that the fracture strains in stretch-bending tests with cylindrical punch are similar to those obtained with the Nakajima test (FLCF). On the other hand, the fracture strains in the SPIF are clearly above FLCF, which means that the bending effect controlled by the ratio of the initial sheet thickness to the tool radius might not be enough to explain the formability in SPIF.
Plasticity concepts and damage and ductile fracture mechanisms were used by Isik et al. [68] to analyse the FLCF and to obtain the shear fracture forming line (SFFL). Then, an experimental methodology was proposed by using SPIF, torsion and plane shear tests to determine the values of the in-plane strains at the onset of fracture. It has been found that there is a good agreement between FLCF established by means of tensile and conventional sheet formability tests and the FLCF constructed by SPIF test on conical and pyramidal truncated specimens (Fig. 16). Also, a fair agreement between experimental and theoretical fundamentals was used to construct SFFL. There are two important considerations that need further clarification in FLCF of SPIF. It is necessary to prove, firstly, whether the Nakajima test is able to capture the fracture occurrence in the SPIF or SPIF test and can be used to establish FLCF, and secondly, whether the FLCF is a straight line in all types of materials or there are some materials which have the FLCF as a curve, as shown in Fig. 15. Also, there is a knowledge gap in the influence of through-thickness stress on the necking and fracture limit. Therefore, further investigations are needed.

\subsubsection{Effect of forming tool on deformation and failure}

Depending on the tool diameter, failure can be predicted; e.g., in the case of large tool diameters, there is an increase in the a

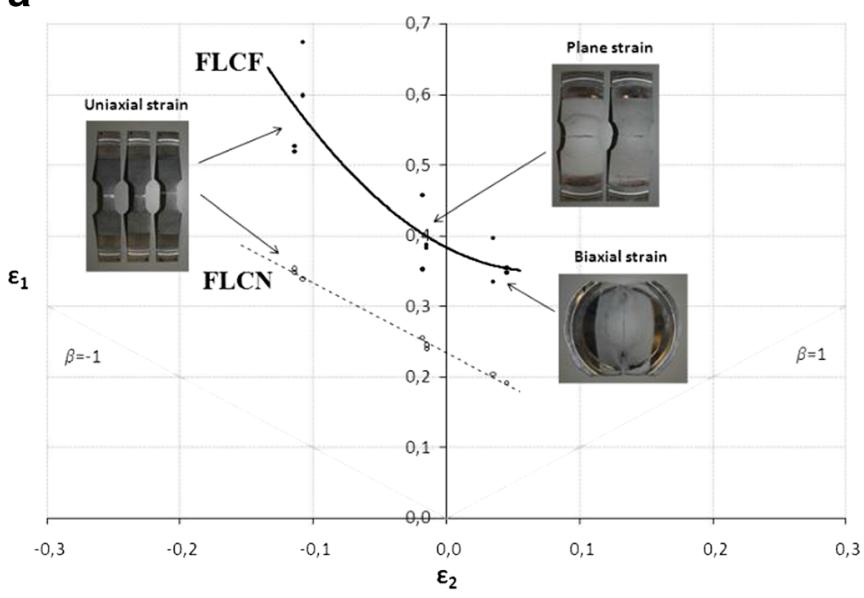

b

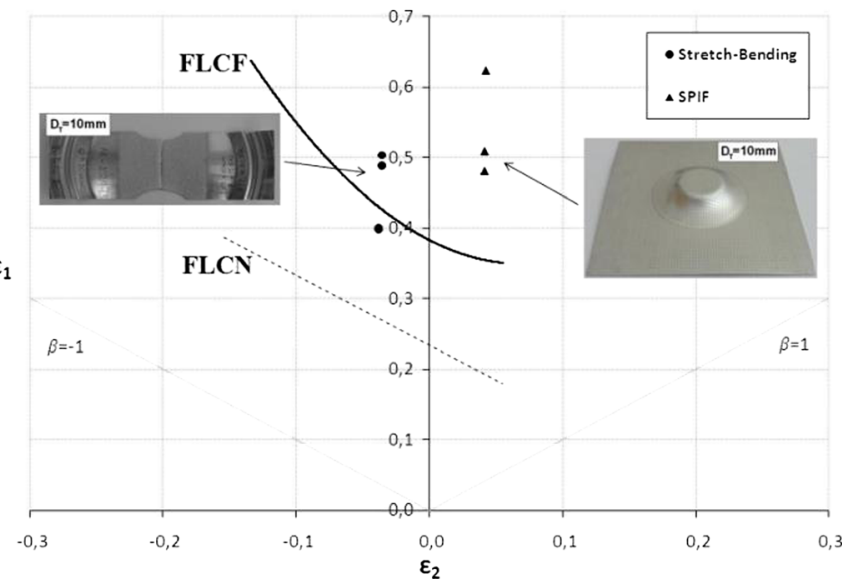

Fig. 15 Forming limit diagrams. a Conventional FLD. b Fracture strains in SPIF and stretch-bending for a tool diameter of $10 \mathrm{~mm}$ [67] 


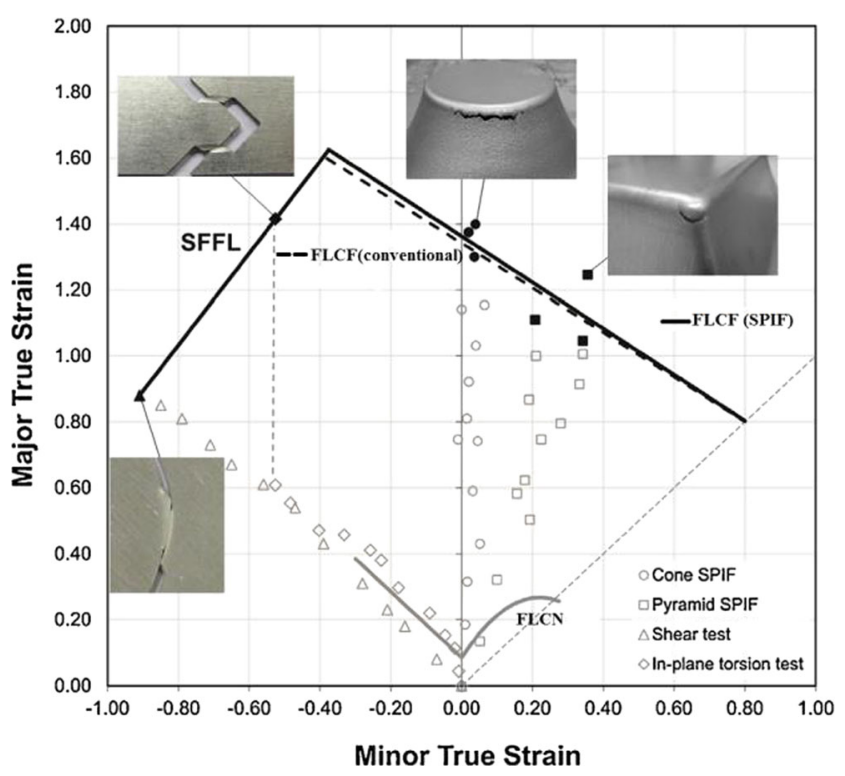

Fig. 16 Determination of the fracture loci (FLCF and SFFL) from the experimental strains at fracture that were obtained from the SPIF and shear tests [68]

amount of forming force because of the increase in contact area between the tool and sheet, and this area can fail due to the high percentage of stresses when compared to another contact area with a small tool diameter. In addition, different types of tools and friction conditions between the tool and sheet play an important role in developing a failure. A tool containing a freely rotating ball was developed and applied by Myoung-Sup and Jong-Jin [2] to characterize the formability of fully annealed AA1050 sheets. The results showed that a near equi-biaxial stretching develops at a corner, while a near plane-strain stretching develops along the straight side, and the deformation of near equi-biaxial stretching is greater than near plane-strain stretching, so the cracks occur mostly at the corners. Numerical simulation was used to determine the condylar surface by Valentin et al. [69] in order to obtain the component of the titanium sheet (Ti-6Al-4V) by ISF. It was noted that the maximum value of strains and stresses was equivalent or principal, and sheet thinning appeared across the tool trajectory along the circumference with the bigger tool diameter. One of the newest methods to produce a knee condylar surface by ISF was developed by Oleksik et al. [70]. $\mathrm{CpTi}$ sheet was examined using numerical simulation. It was identified that the maximum values of sheet thinning and principal strains appeared across the punch trajectory on the circumference with the biggest diameter. Furthermore, the sheet thickness was a parameter with the greatest effect on the studied parameters. Silva et al. [71] revisited failure in SPIF and presented a new understanding of the effect of process parameters, such as tool size, that helped researchers to propose a new unified view on formability limit and fracture in SPIF. Aluminium AA1050-H111 sheets were used in this study. The research work allowed the possibility to determine a critical threshold for the ratio of the thickness of the sheet to the radius of the tool (incremental tool ratio) that distinguishes between fractures, with and without prior necking, as shown in Fig. 17. Failure in SPIF was revisited by means of experimental analysis by Centeno et al. [72]. This investigation explained the effect of process parameters, such as forming tool radius on the formability of SPIF of stainless steel AISI304. Nakajima test was performed and compared with SPIF and stretchbending test to measure the effect of bending in FLD strains. The results showed that in SPIF, the enhancement of formability above the FLCN increased as tool size decreases up to values around $150 \%$ with tool diameter of $6 \mathrm{~mm}$, while in the stretch-bending it remained around $30 \%$ for both tool
Fig. 17 Incremental tool ratio $\left(\mathrm{r}_{\text {part }} / \mathrm{r}_{\text {tool }}\right)$ as a function of tool radius for the SPIF of truncated conical shapes [71]

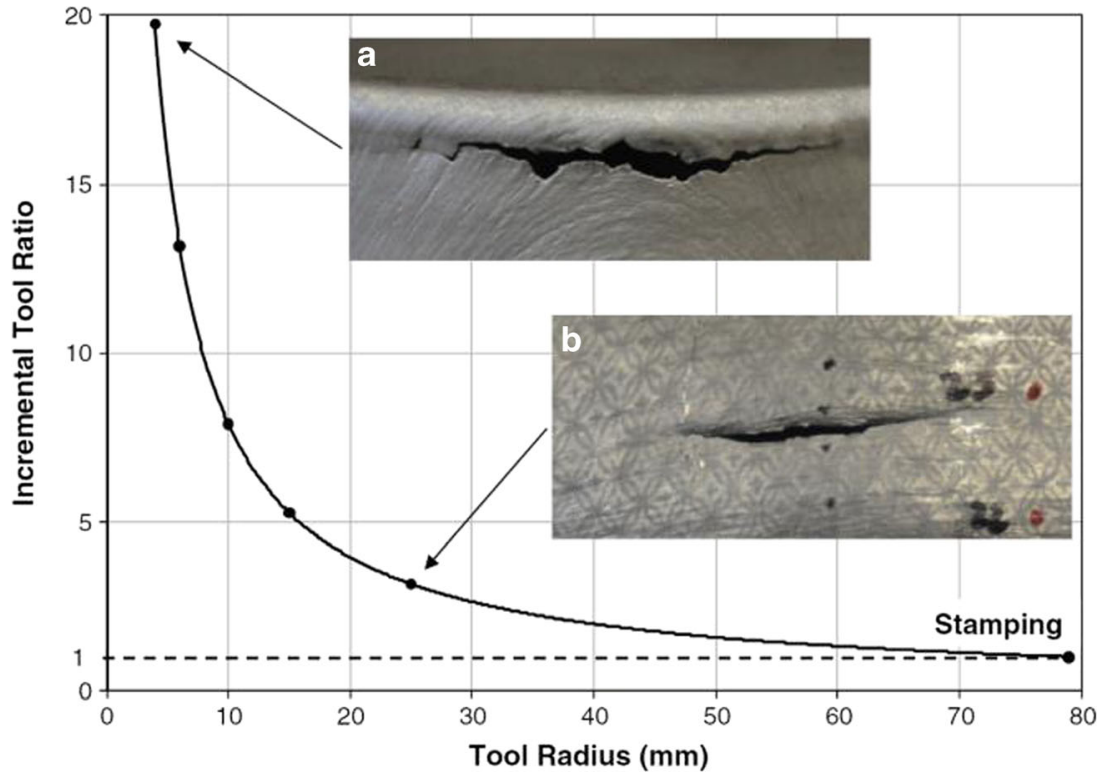


diameters (10 and $20 \mathrm{~mm}$ ). Also, it was noted that with small tool size, the fracture strains in stretch-bending were located near to FLCF produced from Nakajima test, but in SPIF the fracture strains were placed above it.

\section{Springback and accuracy in SPIF}

After forming operation, when the forming loads are removed, an undesirable shape change occurs due to "springback". Such a springback deformation leads to deviations from the desired shape. In traditional sheet metal forming, the contact area between the forming tools and sheet throughout the forming processes is large, and the springback is obtained when the tools are removed. Consequently, efforts were made to investigate the springback after removing the loads. On the other hand, in ISF the contact area between the tool and sheet is small and usually the deformed parts need to cut to produce the final shape. Therefore, there are three types of springback in ISF: the first happens simultaneously with the displacement of the tool, which is called a continuous local springback. The second is a global springback that occurs when the loads are removed and dismounted from clamps; and the last is a global springback which takes place after trimming (if done) [8]. In the SPIF process, there are many factors affecting springback values, e.g. tool path, sheet thickness, feed rate, spindle speed, tool size, step size and residual stresses. Some effects of these parameters are outlined below.

\subsection{Effect of process parameters on springback and accuracy}

\subsubsection{Tool path}

Accurate prediction of springback is essential for the design of tool path in ISF, so that it can be used to compensate for the springback value by the modification of the tool path. Elastic springback in an aluminium AA1050-O sheet was evaluated and compensated for by Ambrogio et al. [73]. It was noted that some errors appeared along the oblique walls in the experiment generating a curvature on the straight sides. This phenomenon is due to the elastic springback, the effect of which is lower in comparison to the edges, where the geometrical stiffness is higher than in other areas, so a numerical/ experimental procedure was developed to limit the shape defects. An FE model based on shell element was proposed by Dejardin et al. [74] to analyse the springback effects of aluminium sheet. It was demonstrated through experiments and FEA that the springback, characterized by means of the cut rings method, can be accurately predicted by using the shell element associated with a suitable tool path. Han et al. [75] developed a coupled closed loop algorithm with a finite element method to simulate a 08Al sheet metal part. Using the wavelet transform combined with a fast Fourier transform, the closed loop algorithm of the tool path was constructed. The result showed that the algorithm could predict an ideal profile of a processing track, and the error of springback was effectively eliminated. A finite element model was developed by Hartley [76] to modify the final stage of the tool path. The results showed that the extension of the tool path across the base of the sheet reduces the pillow effect at the sheet centre. Gong [77] published another research study based on the wavelet and fast Fourier transforms, to develop an algorithm for closed loop tool trajectory taking springback into account. However, the tool path is corrected based on the data of the springback shapes after unloading. It was found that the tool path correction algorithm with Fourier and wavelet transforms was reasonable. Lu et al. [78] presented a new feature-based tool path generation algorithm for ISF technology. Better geometric accuracy can be obtained by using this feature-based algorithm, especially for the cases of non-symmetrical parts without a supporting die. Future work should focus on new algorithms that take into account the effect of materials' properties and forming parameters in order that it can be used to compensate for springback after trimming.

\subsubsection{Forming parameters}

Recent researches indicate that there are five factors, namely, sheet metal thickness, feed rate, spindle speed, tool size and incremental depth that affect springback. Oleksik et al. [70] employed a numerical simulation method for producing the knee condylar surface by using ISF to form Cp Ti sheet. The results showed that the global springback value increased with the increase of the tool size and decrease of the step size and sheet thickness. Springback and its effect on geometrical and dimensional accuracy of ISF technology were investigated by Mehdi et al. [79], and an analytical model was obtained to select the appropriate process parameters for reduced springback. It was found that increases of tool diameter, feed rate, spindle speed and sheet thickness with a reduction in vertical step size can lead to the reduction of springback, independently. Junchao et al. [28] utilized a DC56 sheet to establish a FEM for multistage ISF technology and experimental verification. It was found that, when the number of forming stages increases, the springback becomes larger, in contrast to a single pass process, due to the accumulation of springback during each forming stage. Furthermore, it was noticed that the magnitude of springback was not related to the incremental wall angle, while the number of forming stages was determined (Fig. 18). Future work should study the effect of forming parameters on springback in descending order depending on its effect. 
a

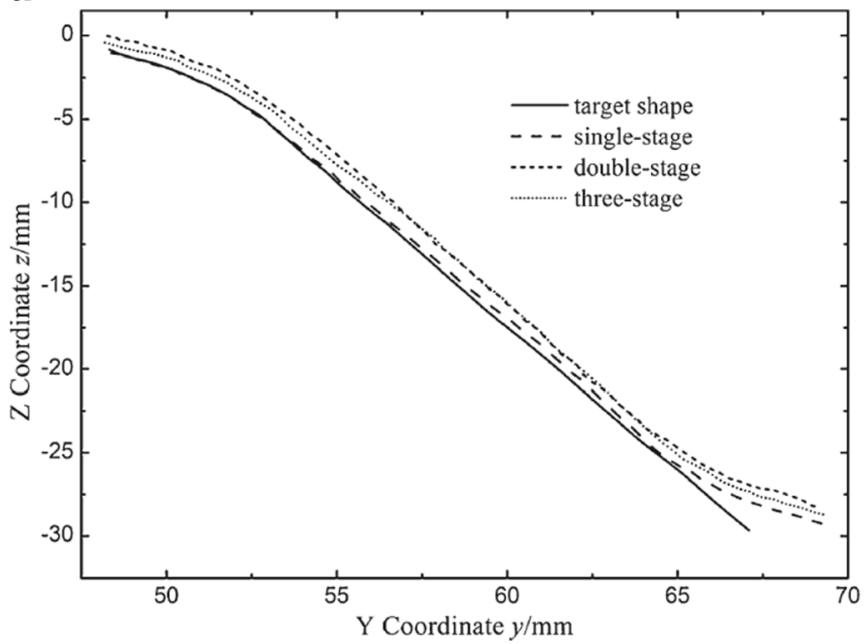

b

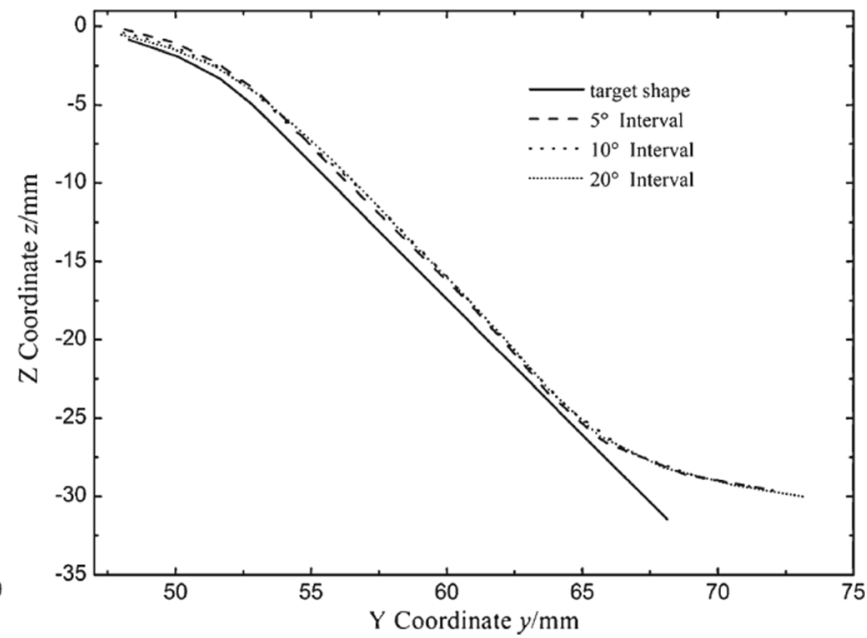

Fig. 18 Sectional profiles at $\mathbf{a}$ different forming processes and $\mathbf{b}$ different angle intervals [28]

\subsubsection{Tensile force}

Three components of force are created during the ISF process, two in the horizontal plane $\left(\mathrm{F}_{\mathrm{x}}\right.$ and $\left.\mathrm{F}_{\mathrm{y}}\right)$ and another one in the vertical direction $\left(\mathrm{F}_{\mathrm{z}}\right)$. These forces could be increased or decreased based on the ISF parameters; e.g. the forming force increases by increasing the step size. Thus, selecting suitable forming parameters help produce favourable amount of forming force to generate less degree of springback. A laser beam was used by Duflou et al. [30] to create a heat spot in the moving contact zone between the tool and sheet (A15182 and $65 \mathrm{Cr} 2)$. The results explained that a moving heated system is able to reduce process force in SPIF. By achieving reduced stress levels and reduced springback, an improved accuracy in ISF can be realised. Pohlak et al. [80] investigated the effect of residual stresses on the geometry of the formed part. It was found that increasing stretching force helps to achieve a more accurate part, as shown in Fig. 19. However, if stretching force is very high, it causes additional problems due to sheet necking. In this field, different types of heat treatment should be used to reduce the residual stresses and to obtain a part with a lesser degree of springback.

\section{Surface roughness in SPIF}

Surface roughness or surface finish is a measure of the texture of a part's surface. It can be expressed by the vertical deviations of a real surface compared to the typical form. There are many different roughness parameters in use, but in ISF, average roughness $\left(R_{a}\right)$ and the parameter of maximum roughness $\left(R_{z}\right)$ are utilized more than the other parameters to determine the values of roughness. Many papers have been published in this field, and all of these papers aimed to achieve reduced surface roughness in ISF. Several parameters were considered to select suitable values in order to achieve a better surface finish, e.g. tool rotation, forming tool, tool path, step size and forming angle.

\subsection{Effect of process parameters on surface roughness}

\subsubsection{Tool rotation and advancement}

Tool rotation has a significant effect on surface quality; the roughness values depend on the direction of tool rotation and the speed of rotation. In addition, XY advancing (feed rate) affects the surface roughness. Tool rotation, advancement in $\mathrm{XY}$ and $\mathrm{Z}$ advancement (step size) were changed by Silva et al. [29] to produce pieces of varying size and complexity in the shortest time and of the highest quality. It was noted that the feed rate below $1200 \mathrm{~mm} / \mathrm{min}$ and incremental depth of $0.2 \mathrm{~mm}$ produced rough surfaces as compared with that obtained at a much higher speed of $8400 \mathrm{~mm} / \mathrm{min}$, for SAE 1008 steel to achieve an acceptable roughness. The applicability of numerical technique was examined by Yamashita et al. [50] for incremental forming of the steel sheet. It was discovered that the surface of the formed pyramid was smoother for a

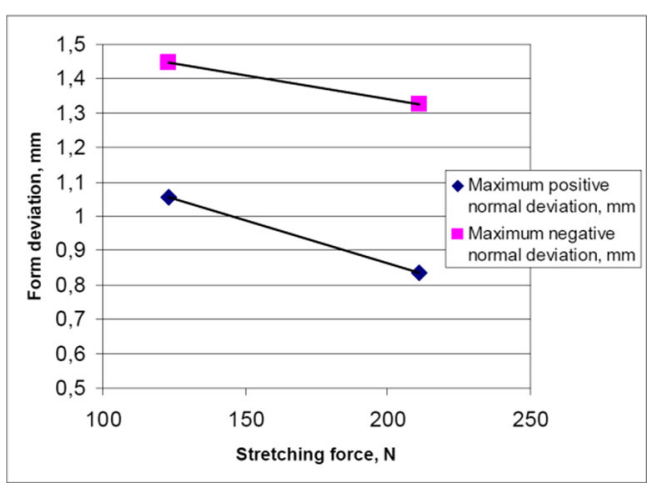

Fig. 19 Form deviation and stretching force relationship [80] 
Fig. 20 Typical roughness profiles measured in: a advancing tool direction (mean value around $0.3 \mu \mathrm{m})$ and $\mathbf{b}$ perpendicular direction (mean value around $0.6 \mu \mathrm{m})[81]$ a

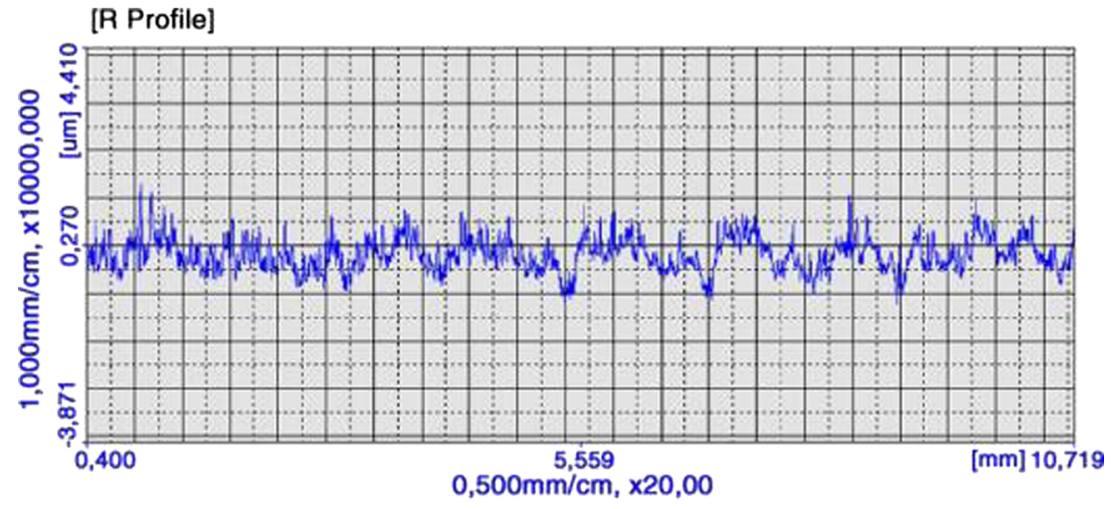

b

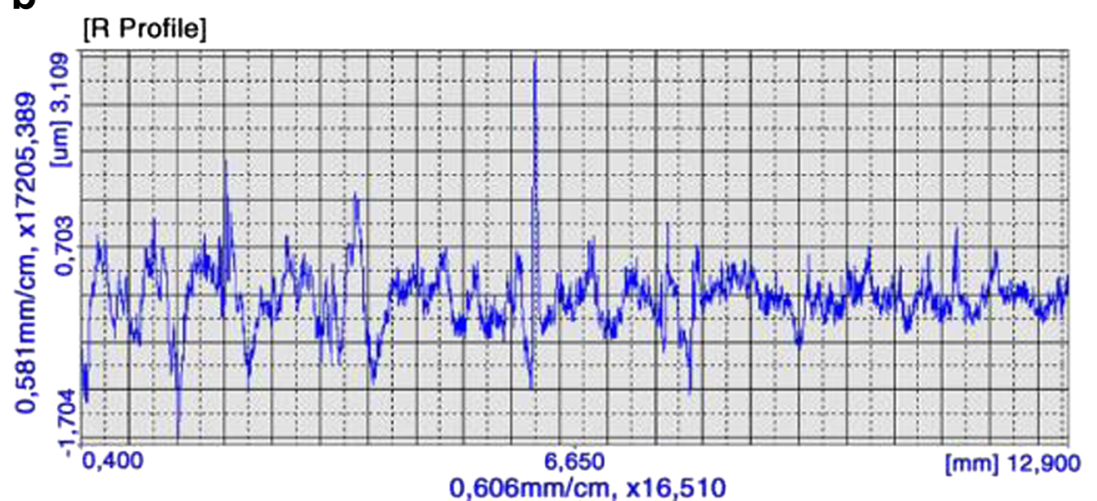

deeper product, due to the fact that the sheet was subjected to a stronger stretching force from a large stroke of the travelling tool in the vertical direction during the process.

Cerro et al. [81] summarized their work from experimental tests and FEM simulation to evaluate the surface roughness of Al 1050-0 sheet in both the tool advancing (feed rate) and in the perpendicular directions (step size). It was shown that the roughness values were always lower in the tool advancing direction than in the perpendicular one. In the first case, the surface roughness was $0.3 \mu \mathrm{m}$, and in the second case $0.6 \mu \mathrm{m}$. Nevertheless, surface roughness can fall by reducing the axial step size (Fig. 20). A study was carried out by Durante et al. [82] in order to evaluate the effect of tool rotation, in terms of speed and direction, in ISF processing of aluminium AA7075-T0 sheets. It was pointed out that roughness values differed depending on whether the tool was rotating or not by using a rotating tool as compared with a non-rotating one. The surface roughness value is reduced by less than $10 \%$ (Fig. 21).

Hamilton and Jeswiet [83] investigated the effect of high feed rate and rotational speeds in SPIF processing of Al3003-H14 sheets. Three criteria were used to examine the formed sheet external non-contact surface roughness (orange peel effect), thickness distribution and sectional microstructure. A model for an equivalent combinatory roughness was created based on Ra and Rz roughness and forming parameters. It was shown that shape factor (a formation of forming angle/tool diameter and incremental depth) had a strong effect on an equivalent roughness as shown in Fig. 22. However, grain structure and thickness distribution remained similar to lower speed forming.

\subsubsection{Tool size and materials}

Both forming tool material and tool size play an important role in the final surface roughness. Therefore, some researchers tried to select the most suitable material and tool diameter to get a better surface finish. Ham et al. [84] used two tools: one was acetal tipped, and the other was a carbide tool to characterize the topography of surfaces created by forming aluminium sheet. It was found that the

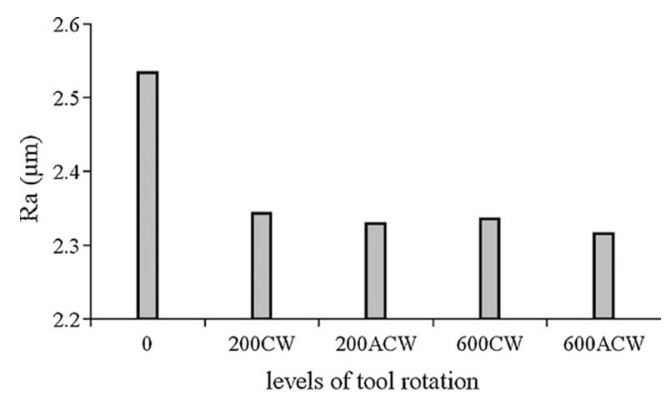

Fig. 21 Roughness for different levels of tool rotation [82] 


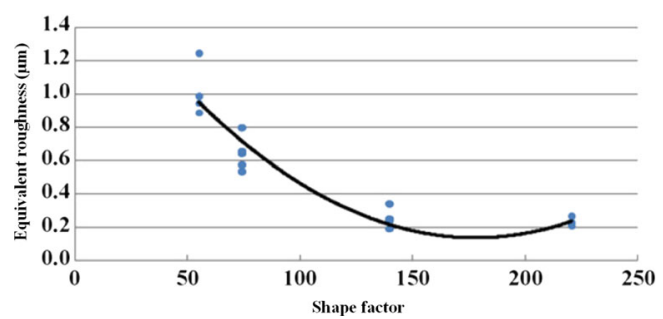

Fig. 22 Sensitivity of roughness to the shape factor [83]

surface roughness and the degree of anisotropy of the surface depended on the forming tool material. The acetal tool did not appear to burnish the surface with which it had contact during forming and thus achieved a less rough surface than using a conventional forming tool. Also, the acetal tool produced a surface that was more cosmetically consistent with unformed sheet metal than the carbide tool. Experimental research was presented by Oleksik et al. [85] to study surface quality of the medical implants used for the partial resurfacing of the femoral condylar surface of the knee. The parts made of titanium (Ti-6Al-4V) were manufactured by SPIF. The roughness of the punch was reduced to improve the surface finish of the part. It was found that the roughness of the interior surface was $\mathrm{Ra}=0.34 \mu \mathrm{m}$, which was comparable with the initial roughness of the titanium sheet $(\mathrm{Ra}=0.25 \mu \mathrm{m})$. Furthermore, the quality of the final part was influenced mainly by the roughness of the tool and friction between the tool and sheet surface but not by the tool diameter. In addition, the external surface of the part (the surface which was not processed) was not affected during the forming process. An experimental study was carried out by Bhattacharya et al. [39] to study the effect of ISF process variables on the surface finish of Al5052. It was found that the surface roughness decreased with an increase in tool size for all incremental depths (Fig. 23). Traditional rigid tool and ORB tool were used by Lu et al.

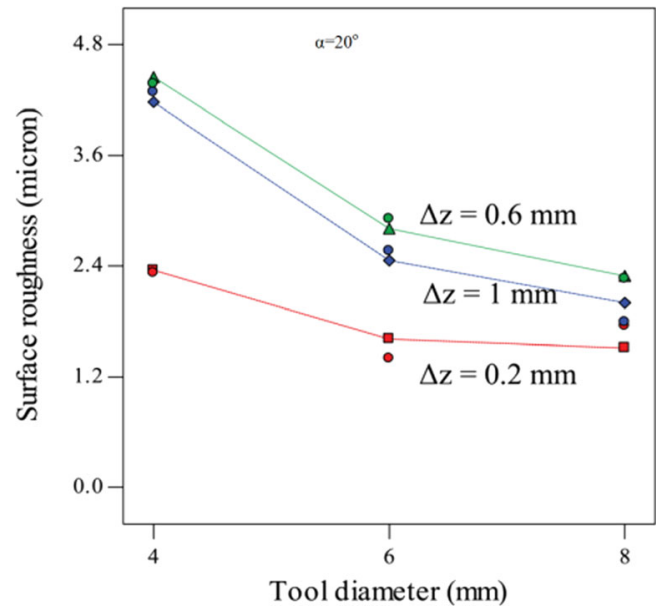

Fig. 23 Variation of surface finish with tool diameter at different incremental depths [39]
[49] to investigate the effect of friction on the surface finish. The results showed that better surface finish can get with the ORB tool.

\subsubsection{Tool path}

Depending on the strategy of the tool path, a high surface quality can be obtained. A new feature-based tool path generation algorithm for ISF technology was presented by Lu et al. [78]; in this algorithm, tool trajectory was created according to the specified critical edges. A better surface finish can be produced at the critical edges by using the feature-based algorithm as compared to the conventional ISF tool path method. This is true for certain non-horizontal edges on the parts. A dedicated program which uses the coordinates from the profile milling code and converts them into a helical tool path with continuous feed in all three directions was offered by Skjoedt et al. [86], who found that scarring was eliminated when using a helical tool path.

\subsubsection{Step size}

Incremental step size has a significant influence on the surface quality in the sense that greater incremental depth can lead to a low surface quality. A white light interferometry scan was used by Hagan and Jeswiet [87] to perform surface roughness tests of CNC ISF using various incremental depths. A relationship between incremental depth and peak-to-valley roughness was defined. It found that the maximum peak-to-valley height increases exponentially as the step size is increased; in depth increment tests, the average roughness values appear to follow the same trend as that of peak-to-valley. Attanasio et al. $[14]$ used a coordinate measuring machine (CMM), with precision of $3.8 \mu \mathrm{m}$, to evaluate the surface quality of the door handle (FeP04 steel sheet). As shown in Fig. 24, incremental depth and maximum scallop height have a great effect on

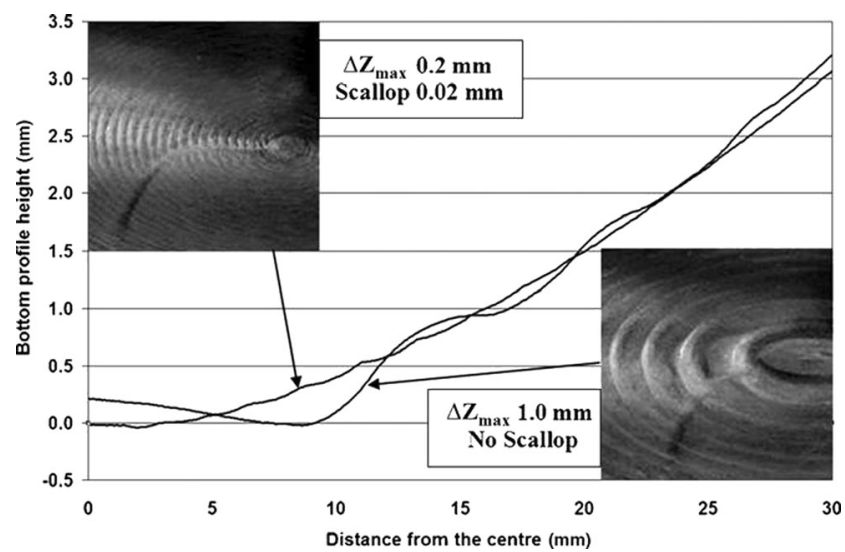

Fig. 24 Bottom profiles measured on the best and the worst performed tests [14] 
surface waviness. Surface waviness drops when low step size values are utilized, even though good results are obtained on inclined walls as compared to flat or near-flat ones. Low values of scallop parameters (less than $0.1 \mathrm{~mm}$ ) produce a more homogeneous surface finish in terms of part quality. To study the effect of ISF process variables on the surface finish of A15052, an experimental study was carried out by Bhattacharya et al. [39]. The results showed that the surface quality decreases first with increases in step size depth up to a certain angle, and then increases.

\subsubsection{Forming angle}

Forming angle is usually used as a measure for the formability and surface finish, because when the wall angle is changed, the roughness values change, due to the change of the stretching values in the part wall. So, when forming angle increases, the stretching increases and a good surface finish may be obtained. However, the high wall angle causes failure, so it should be selected carefully. By using different process variables, Bhattacharya et al. [39] conducted an experimental study to investigate the effect of ISF on surface quality of A15052. They found that the surface quality increases with the increase in wall angle. Hot ISF was investigated by Ambrogio et al. [88]. In their study, three lightweight alloys, including aluminium AA2024-T3, magnesium AZ31B-O and titaniumTi6A14V, were formed by SPIF using continuous current in order to achieve local heating. The results showed that the surface quality deteriorated by increasing the forming angle. Titanium F67 grade 2 sheet for medical implant was formed by SPIF, and internal and external roughness was measured by Daleffe et al. [89]. The roughness of three sheets was measured with a changing angle of $45^{\circ}, 47^{\circ}$ and $48^{\circ}$. Roughness in the unformed sheet was $2 \mu \mathrm{m}$. It was proven that, on the part of the sheet which came into contact with the tool, roughness was $5.19 \mu \mathrm{m}$ greater than that on the opposite side with a value $4.50 \mu \mathrm{m}$, as shown in Table 1.

\section{Summary}

SPIF is a highly flexible method for rapid manufacturing of sheet metal parts due to the fact that complex geometries can be formed by moving the tool in a programmed path without the need for specific tooling or a die. Many papers have been published in this field which share one target, namely, to understand the mechanisms of SPIF and to obtain a part of sufficient quality and accuracy without defects. By presenting an overview on the state of the art of the SPIF process with a particular attention on the effects of ISF process parameters, conclusions and recommendation for future work can be made in the following areas.

\subsection{Formability}

- Full formability of hard-to-form materials can be used with hot ISF.

- More uniform thickness can be achieved with double or multi-pass forming.

- SPIF achieves high strain as compared to traditional sheet metal forming.

- Maximum principal strain and sheet thinning appear across the tool trajectory on the circle circumference with the large tool size.

- Forming angle increases when using a small tool size with a helical tool path.

- Step size and feed rate have little effect on maximum wall angle.

- The influence of step size as a process parameter is still debatable; some researchers claim that the step size does not affect formability, while others believe that an increased step size has a negative effect on formability.

- Better formability is obtained when increasing the rotational speed and decreasing the feed rate of the tool.

- Tool diameter has little effect on the location of minimum thickness, but it seems that an increased tool diameter with a helical tool path has a positive effect to the even thickness distribution.

Table 1 Roughness results [89]

\begin{tabular}{|c|c|c|c|c|c|c|c|}
\hline \multirow[t]{2}{*}{ Measured faces } & \multicolumn{2}{|c|}{$45^{\circ}(\mu \mathrm{m})$} & \multicolumn{2}{|l|}{$47^{\circ}(\mu \mathrm{m})$} & \multicolumn{2}{|c|}{$48^{\circ}(\mu \mathrm{m})$} & \multirow{2}{*}{$\begin{array}{l}\text { Flat sheet Rm } \\
(\mu \mathrm{m})\end{array}$} \\
\hline & $\begin{array}{l}\text { Face } \\
\text { ext. }\end{array}$ & $\begin{array}{l}\text { Face } \\
\text { int. }\end{array}$ & $\begin{array}{l}\text { Face } \\
\text { ext. }\end{array}$ & $\begin{array}{l}\text { Face } \\
\text { int. }\end{array}$ & $\begin{array}{l}\text { Face } \\
\text { ext. }\end{array}$ & $\begin{array}{l}\text { Face } \\
\text { int. }\end{array}$ & \\
\hline 1 & 4.10 & 6.60 & 5.45 & 5.50 & 5.35 & 4.10 & \\
\hline 2 & 4.60 & 5.30 & 5.20 & 6.10 & 5.25 & 4.80 & \\
\hline 3 & 3.30 & 5.15 & 4.20 & 3.90 & 4.60 & 5.30 & \\
\hline 4 & 4.60 & 4.40 & 3.10 & 5.30 & 4.30 & 5.90 & \\
\hline $\begin{array}{l}\text { Mean roughness } \mathrm{Rm} \\
\quad(\mu \mathrm{m})\end{array}$ & 4.15 & 5.36 & 4.48 & 5.20 & 4.87 & 5.02 & \\
\hline
\end{tabular}


- More uniform thickness can be achieved with a helical tool path and parallel line type tool trajectory.

\subsection{Deformation and failure mechanics}

- It can be determined from the membrane analysis and experimental observations that fracture is not preceded by localized necking and that a crack develops in the meridional direction under tensile stresses acting under stretching conditions.

- Local bending and through-the-thickness shear have an effect on fracture in the SPIF.

- The probability of fracture occurring increases with large tool sizes as compared to small ones.

- Fracture mostly occurs at the corner of the part due to the fact that near equi-biaxial stretching is greater than near plane-strain stretching.

\subsection{Springback and accuracy}

- Springback can be reduced by using an algorithm to compensate for the springback and modify the tool path.

- Increasing tool diameter, feed rate, spindle speed and sheet thickness and reducing vertical step size can lead to a reduction in springback.

- Springback can be decreased with an increase of the tensile force in the wall of the deformed part.

\subsection{Surface roughness}

- Both tool rotation and advancement have an effect on surface quality; the surface roughness is reduced by using a rotating tool as compared with the use of a non-rotating one. On the other hand, roughness values are always lower in the tool advancing direction than in the perpendicular one.

- Surface roughness increases with the increased tool size.

- Parts without scarring can be obtained by using a helical tool path.

- Greater incremental depth can lead to low surface quality.

\section{Recommendations for future work}

In light of extensive research on ISF processes, there are a number of research questions still to be answered; thus, future work is needed in the following areas:
- A new unified model of deformation could be developed to determine whether the deformation occurs due to shearing or through stretching.

- Many parameters have a big effect on the wall angle, e.g. tool diameter and tool path, and future work is needed to quantify the effects on the wall angle such as the step size and feed rate.

- There is a knowledge gap in the influence of step size on the ISF, so future work should focus on its effect from different materials. Furthermore, establishing a relationship between the step size and material types is a possible focus.

- Future work on the effect of tool rotation may be made in the following areas. Firstly, the effect of tool rotation on ISF formability and its effect on sheet metal type should be studied; secondly, there should be a focus on finding a relationship between tool rotation and feed rate; finally, a table of suitable tool rotations and feed rates may be developed as a guide for some important materials used in ISF processes.

- There is a lack of a unified theory for the failure in SPIF. Thus, it is highly desirable that a new theoretical model can be constructed to predict fracture in SPIF using a wide range of process variables, such as wall angle, step size, tool rotation and feed rate.

- A study on the effect of material anisotropy on the location of fracture in SPIF is recommended.

- There are two important questions which need to be clarified in the FLCF of SPIF. The first is whether the Nakajima test is able to capture the fracture occurrence in the SPIF, or if a SPIF test should be used to establish FLCF. The second is whether the FLCF is a straight line in all types of materials or there are some materials which have the FLCF as a curve, as shown in Fig. 15.

- Further investigation should be carried out into the effect of initial sheet thickness to tool radius ratio $\left(\mathrm{t}_{\mathrm{o}} / \mathrm{R}\right)$ on the FLCF, and whether it is enough to describe FLCF in SPIF.

- It is highly desirable to develop a new algorithm to predict springback with the consideration of the effect of materials' properties and forming parameters to compensate the springback after trimming.

- There is a considerable scope of looking into using different types of heat treatment to reduce the residual stresses and obtain a part with a lesser degree of springback.

- The surface finish and dimensional accuracy of an ISF part could be improved by using different algorithms to generate the tool path, several types of lubricant and new tool designs and materials.

Acknowledgements The first author gratefully acknowledges the support provided by the Iraqi Ministry of Higher Education and Scientific Research (IMHESR) for funding this work through scholarship no. 4720. This work was supported by the Engineering and Physical Sciences 
Research Council (EPSRC) of the UK (EP/L02084X/1), International Research Staff Exchange Scheme (IRSES, MatProFuture project, 318,968) within the 7th European Community Framework Programme (FP7).

Open Access This article is distributed under the terms of the Creative Commons Attribution 4.0 International License (http:// creativecommons.org/licenses/by/4.0/), which permits unrestricted use, distribution, and reproduction in any medium, provided you give appropriate credit to the original author(s) and the source, provide a link to the Creative Commons license, and indicate if changes were made.

\section{References}

1. Hirt G, Bambach M (2012) Incremental Sheet Forming. In: Altan T, Tekkaya AE (eds) Sheet metal forming: processes and applications. ASM International, Materials Park, Ohio

2. Myoung-Sup S, Jong-Jin P (2001) The formability of aluminum sheet in incremental forming. J Mater Process Technol 113:654 658

3. Tisza M (2012) General overview of sheet incremental forming. JAMME 55/1:113-120

4. Leszak, E. (1967). Apparatus and process for incremental dieless forming United states patent office.

5. Mason, B. (1978). Sheet metal forming small batches. Bachelor's thesis, University of Nottingham.

6. Appleton E, Mason B (1984) Sheetmetal forming for small batches using sacrificial tooling. Production Eng 63(9):58-61

7. Hagan E, Jeswiet J (2003) A review of conventional and modern single-point sheet metal forming methods. J Eng Manuf 217 Part B: 213-225

8. Jeswiet J, Micari F, Hirt G, Bramley A, Duflou J, Allwood J (2005) Asymmetric single point incremental forming of sheet metal. CIRP Ann Manuf Technol 54(2):88-114

9. Micari F, Ambrogio G, Filice L (2007) Shape and dimensional accuracy in single point incremental forming: state of the art and future trends. J Mater Process Technol 191(1-3):390-395

10. Emmens WC, van den Boogaard AH (2009) An overview of stabilizing deformation mechanisms in incremental sheet forming. $\mathrm{J}$ Mater Process Technol 209(8):3688-3695

11. Emmens WC, Sebastiani G, van den Boogaard AH (2010) The technology of Incremental Sheet Forming - a brief review of the history. J Mater Process Technol 210(8):981-997

12. Taleb Araghi B, Göttmann A, Bambach M, Hirt G, Bergweiler G, Diettrich J, Steiners M, Saeed-Akbari A (2011) Review on the development of a hybrid incremental sheet forming system for small batch sizes and individualized production. Prod Eng 5(4): 393-404

13. Lora FA, Boff U, Yurgel CC, Folle LF, Schaeffer L (2013) Validation of the computer simulation process applied to the incremental forming process for the evaluation of strain paths. Key Eng Mater 554-557:2453-2461

14. Attanasio A, Ceretti E, Giardini C, Mazzoni L (2008) Asymmetric two points incremental forming: improving surface quality and geometric accuracy by tool path optimization. J Mater Process Technol 197(1-3):59-67

15. Jeswiet J, Young D (2005) Forming limit diagrams for single-point incremental forming of aluminium sheet. Proc Inst Mech Eng B J Eng Manuf 219(4):359-364

16. Verbert J, Belkassem B, Henrard C, Habraken A, Gu J, Sol H, Lauwers B, Duflou J (2008) Multi-Step toolpath approach to overcome forming limitations in single point incremental forming. Int $\mathbf{J}$ Mater Form 1(1):1203-1206
17. Luigino F, Giusy A, Manlio G (2013) Optimised tool-path design to reduce thinning in incremental sheet forming process. Int $\mathrm{J}$ Mater Form 6:173-178

18. Schaeffer, L., Castelan, J., Gruber, V., Daleffe, A., \& Marcelino, R. development of customized products through the use of incremental sheet forming for medical orthopadic application. 3rd International Conference on Integrity, Reliability and Failure, Porto/Portugal, 2009(Paper Ref: S0209 P0308): p. 1-12.

19. Decultot N, Robert L, Velay V, Bernhart G (2010) Single point incremental sheet forming investigated by in-process 3D digital image correlation. EPJ Web Conf 6:11001

20. Martins PAF, Bay N, Atkins AG, Skjoedt M, Silva MB (2008) Single-point incremental forming and formability-failure diagrams. J Strain Anal Eng Design 43(1):15-35

21. Allwood JM, Shouler DR, Tekkaya AE (2007) The increased forming limits of incremental sheet forming processes. Key Eng Mater 344:621-628

22. Silva MB, Skjoedt M, Martins PAF, Bay N (2008) Revisiting the fundamentals of single point incremental forming by means of membrane analysis. Int J Mach Tool Manu 48:73-83

23. Saad A (2012) Single point incremental point, in Department of Industrial Engineering And Production. Kth Royal Institute of Technology, Stockholm, Sweden

24. Kim TJ, Yang DY (2000) Improvement of formability for the incremental sheet metal forming process. Int J Mech Sci 42:12711286

25. Han F, Mo J-h (2008) Numerical simulation and experimental investigation of incremental sheet forming process. J Cent S Univ Technol 15(5):581-587

26. Jun-chao L, Chong L, Zhou T-g (2012) Thickness distribution and mechanical property of sheet metal incremental forming based on numerical simulation. Trans Nonferrous Metals Soc China 22:s54 s60

27. Junchao L, Jianbiao H, Junjie P, Pei G (2012) Thickness distribution and design of a multi-stage process for sheet metal incremental forming. Int J Adv Manuf Technol 62:981-988

28. Junchao L, Geng P, Shen J (2013) Numerical simulation and experimental investigation of multistage incremental sheet forming. Int $\mathrm{J}$ Adv Manuf Technol 68(9-12):2637-2644

29. Silva PJ, Leodido LM, Silva CRM (2013) Analysis of incremental sheet forming parameters and tools aimed at rapid prototyping. Key Eng Mater 554-557:2285-2292

30. Duflou JR, Callebaut B, Verbert J, De Baerdemaeker H (2007) Laser assisted incremental forming: formability and accuracy improvement. CIRP Ann Manuf Technol 56(1):273-276

31. Ji YH, Park JJ (2008) Formability of magnesium AZ31 sheet in the incremental forming at warm temperature. J Mater Process Technol 201(1-3):354-358

32. Fan G, Gao L, Hussain G, Wu Z (2008) Electric hot incremental forming: a novel technique. Int J Mach Tools Manuf 48(15):1688 1692

33. Liu, R., Lu B., Xu D., Chen, J., Chen, F., Ou, H., Long, H. (2015). Development of novel tools for electricity-assisted incremental sheet forming of titanium alloy. Int J Adv Manuf Tech, in-press, p. 1-8.

34. Göttmann A, Diettrich J, Bergweiler G, Bambach M, Hirt G, Loosen P, Poprawe R (2011) Laser-assisted asymmetric incremental sheet forming of titanium sheet metal parts. Prod Eng 5(3):263271

35. Mosecker L, Göttmann A, Saeed-Akbari A, Bleck W, Bambach M, Hirt G (2013) Deformation mechanisms of Ti6Al4V sheet material during the incremental sheet forming with laser heating. Key Eng Mater 549:372-380

36. Adams D, Jeswiet J (2014) Single-point incremental forming of 6061-T6 using electrically assisted forming methods. J Eng Manuf 228(7):757-764 
37. Ham M, Jeswiet J (2006) Single point incremental forming and the forming criteria for AA3003. CIRP Ann Manuf Technol 55(1):241244

38. Minutolo FC, Durante M, Formisano A, Langella A (2007) Evaluation of the maximum slope angle of simple geometries carried out by incremental forming process. J Mater Process Technol 194(1-3):145-150

39. Bhattacharya A, Maneesh K, Venkata Reddy N, Cao J (2011) Formability and surface finish studies in single point incremental forming. J Manuf Sci Eng 133(6):061020

40. Radu C (2011) Determination of the maximum forming angle of some carbon steel metal sheet. J Eng Stud Res 17:71-74

41. Fritzen D, Daleffe A, Castelan J, Schaeffer L (2013) Brass 70/30 and incremental sheet forming process. Key Eng Mater 554-557: 1419-1431

42. Ambrogio, G., L. Filice, L., Fratini, and Micari, F. (2004). Process mechanics analysis in single point incremental forming. in MATERIALS PROCESSING AND DESIGN: Modeling, Simulation and Applications-NUMIFORM 2004-Proceedings of the 8th International Conference on Numerical Methods in Industrial Forming Processes. AIP Publishing 712(1) p.922-927.

43. Kim YS, Lee HJ, Park JG, Nguyen DT (2010) Finite element method study of incremental sheet forming for complex shape and its improvement. Proc Inst Mech Eng B J Eng Manuf 224(6):913-924

44. Hussain G, Gao L, Zhang ZY (2008) Formability evaluation of a pure titanium sheet in the cold incremental forming process. Int $\mathrm{J}$ Adv Manuf Technol 37:920-926

45. Duflou J, Tunçkol Y, Szekeres A, Vanherck P (2007) Experimental study on force measurements for single point incremental forming. J Mater Process Technol 189(1-3):65-72

46. Rattanachan K, Chungchoo C (2009) Formability in single point incremental forming of dome geometry. AIJSTPME 2(4):57-63

47. Buffa G, Campanella D, Fratini L (2013) On the improvement of material formability in SPIF operation through tool stirring action. Int J Adv Manuf Technol 66(9-12):1343-1351

48. Ham M, Jeswiet J (2007) Forming limit curves in single point incremental forming. CIRP Ann Manuf Technol 56(1):277-280

49. Lu B, Fang Y, Xu D, Chen J, Ou H, Moser N, Cao J (2014) Mechanism investigation of friction-related effects in single point incremental forming using a developed oblique roller-ball tool. Int $\mathrm{J}$ Mach Tools Manuf 85:14-29

50. Yamashita M, Gotoh M, Atsumi S-Y (2008) Numerical simulation of incremental forming of sheet metal. J Mater Process Technol 199(1-3):163-172

51. Zhou LR (2011) Study on mechanism of NC sheet metal incremental forming. Adv Mater Res 239-242:940-943

52. Azaouzi M, Lebaal N (2012) Tool path optimization for single point incremental sheet forming using response surface method. Simul Model Pract Theory 24:49-58

53. Liu Z, Li Y, Meehan PA (2013) Experimental investigation of mechanical properties, formability and force measurement for AA7075-O aluminum alloy sheets formed by incremental forming. Int J Precis Eng Manuf 14(11):1891-1899

54. SY, L.V. (2009). Modeling of single point incremental forming process for metal and polymeric sheet in Department of Innovation in Mechanics and Management. PhD thesis, University of Padova.

55. Martins PAF, Bay N, Skjoedt M, Silva MB (2008) Theory of single point incremental forming. CIRP Ann Manuf Technol 57(1):247252

56. SIMULIA, ABAQUS 6.13, Alalysis User's Manual. 2013.

57. Jackson K, Allwood J (2009) The mechanics of incremental sheet forming. J Mater Process Technol 209(3):1158-1174

58. Malhotra, R., Xue, L., Cao, J., and Belytschko, T. (2011). Identification of Deformation Mechanisms Responsible for
Failure in Incremental Forming using a Damage Based Fracture Model. Proc. Numisheet2011 conf, Seoul, South Korea,p. 469-476.

59. Malhotra R, Xue L, Belytschko T, Cao J (2012) Mechanics of fracture in single point incremental forming. J Mater Process Technol 212(7):1573-1590

60. Guzmán CF, Habraken AM (2013) Towards fracture prediction in single point incremental forming. Key Eng Mater 554-557:23552362

61. Xu, D., Malhotra, R., Chen, J., Lu, B., and Cao J. (2013). Numerical and experimental studies for the effects of through-the-thickness shear on formability in single point incremental forming. AIP Conf Proc, p. 969-976.

62. Fang Y, Lu B, Chen J, Xu DK, Ou H (2014) Analytical and experimental investigations on deformation mechanism and fracture behavior in single point incremental forming. J Mater Process Technol 214(8):1503-1515

63. Câmara, J.L.P.d.B., (2009). Single Point Incremental Forming, in Engenharia Mecânica. MSc thesis, Danmarks Tekniske Universitet.

64. Han HN, Kim K-H (2003) A ductile fracture criterion in sheet metal forming process. J Mater Process Technol 142(1):231-238

65. Araujo, R., P. Teixeira, L. Montanari, A. Reis, M.B. Silva, and P.A. Martins. (2013). Single point incremental forming of a facial implant. Prosthet Orthot Int 38(5):369-78.

66. Nguyen D-T, Kim Y-S (2013) A numerical study on establishing the forming limit curve and indicating the formability of complex shape in incremental sheet forming process. Int J Precis Eng Manuf 14(12):2087-2093

67. Centeno G, Martínez-Donaire AJ, Vallellano C, Martínez-Palmeth LH, Morales D, Suntaxi C, García-Lomas FJ (2013) Experimental study on the evaluation of necking and fracture strains in sheet metal forming processes. Procedia Engineering 63:650-658

68. Isik K, Silva MB, Tekkaya AE, Martins PAF (2014) Formability limits by fracture in sheet metal forming. J Mater Process Technol 214(8):1557-1565

69. Valentin SO, Adrian MP, Cristian VD, Radu F, Mihai R (2009) Numerical simulation of the incremental forming process for knee implants. X International Conference on Computational Plasticity, CIMNE, Barcelona, pp 1-4

70. Oleksik V, Pascu A, Deac C, Fleaca R, Roman M, Bologa O (2010) The influence of geometrical parameters on the incremental forming process for knee implants analyzed by numerical simulation. NUMIFORM 2010:1208-1215

71. Silva MB, Nielsen PS, Bay N, Martins PAF (2011) Failure mechanisms in single-point incremental forming of metals. Int $\mathrm{J}$ Adv Manuf Technol 56(9-12):893-903

72. Centeno G, Bagudanch I, Martínez-Donaire AJ, García-Romeu ML, Vallellano C (2014) Critical analysis of necking and fracture limit strains and forming forces in single-point incremental forming. Mater Des 63:20-29

73. Ambrogio G, Costantino I, De Napoli L, Filice L, Fratini L, Muzzupappa M (2004) Influence of some relevant process parameters on the dimensional accuracy in incremental forming: a numerical and experimental investigation. J Mater Process Technol 153154:501-507

74. Dejardin S, Thibaud S, Gelin JC, Michel G (2010) Experimental investigations and numerical analysis for improving knowledge of incremental sheet forming process for sheet metal parts. J Mater Process Technol 210(2):363-369

75. Han F, Mo J-h, Gong P, Li M (2011) Method of closed loop springback compensation for incremental sheet forming process. J Cent S Univ Technol 18(5):1509-1517

76. Hartley KEP (2011) An assessment of various process strategies for improving precision in single point incremental forming. Int $\mathrm{J}$ Mater Form 4:401-412 
77. Gong ZFJMFHP (2013) Tool path correction algorithm for singlepoint incremental forming of sheet metal. Int J Adv Manuf Technol 64:1239-1248

78. Lu B, Chen J, Ou H, Cao J (2013) Feature-based tool path generation approach for incremental sheet forming process. J Mater Process Technol 213(7):1221-1233

79. Mehdi V, Mohammad S, Hossein K (2010) An analytical model to reduce spring-back in incremental sheet metal forming (ISMF) process. Adv Mater Res 83-86:1113-1120

80. Pohlak, M., Küttner, R., Majak, J., Karjust, K., and Sutt, A. (2004). experimental study of incremental forming of sheet metal product. 4th International DAAAM Conference, (Inddustrial EngineeringInnovation as competitve Edge for SMES): Tallinn, Estonia, Citeseer, p. 139-142.

81. Cerro I, Maidagan E, Arana J, Rivero A, Rodríguez PP (2006) Theoretical and experimental analysis of the dieless incremental sheet forming process. J Mater Process Technol 177(1-3):404-408

82. Durante M, Formisano A, Langella A, Capece Minutolo FM (2009)

The influence of tool rotation on an incremental forming process. J Mater Process Technol 209(9):4621-4626
83. Hamilton K, Jeswiet J (2010) Single point incremental forming at high feed rates and rotational speeds: surface and structural consequences. CIRP Ann Manuf Technol 59:311-314

84. Ham M, Powers BM, Loiselle J (2013) Surface topography from single point incremental forming using an acetal tool. Key Eng Mater 549:84-91

85. Oleksik V, Pascu A, Deac C, Fleacă R, Bologa O, Racz G (2010) Experimental study on the surface quality of the medical implants obtained by single point incremental forming. Int $\mathrm{J}$ Mater Form 3(S1):935-938

86. Skjoedt M, Hancock MH, Bay N (2007) Creating helical tool paths for single point incremental forming. Key Eng Mater 344:583-590

87. Hagan E, Jeswiet J (2004) Analysis of surface roughness for parts formed by computer numerical controlled incremental forming. $\mathrm{J}$ Eng Manuf 218(Part B):1307-1312

88. Ambrogio G, Filice L, Gagliardi F (2012) Formability of lightweight alloys by hot incremental sheet forming. Mater Des 34: 501-508

89. Daleffe A, Schaeffer L, Fritzen D, Castelan J (2013) Analysis of the incremental forming of titanium F67 grade 2 sheet. Key Eng Mater 554-557:195-203 